\title{
WHAT 'IF'? \\ THE EMERGING EPISTEMIC COMMUNITY OF INTERNATIONAL CRIMINAL LAW
}

\author{
Jakob v. H. Holtermann ${ }^{*} \&$ Anne Lise Kjær ${ }^{\dagger \ddagger}$
}

Using international criminal law as a case study, this article aims to demonstrate how computer-assisted corpus linguistics combined with philosophy of law and sociology of science can help improve our understanding of legal knowledge and science. The article is built on a computer-driven corpus linguistic study of all judgements from the International Criminal Tribunal for the former Yugoslavia (ICTY) and the International Criminal Tribunal for Rwanda (ICTR) from 1996 to 2017. To our surprise, this study revealed that the frequency of the use of 'ifs' in all judgements had exhibited an almost perfectly steady annual decline - from 93 per 100,000 words on average in 1996 to 34 in 2017. As a linguistic phenomenon, this contradicts how we would expect language to behave. In the search for an explanation, we move from linguistics into the philosophical and sociological study of (legal) knowledge and science. In the most general terms, the explanation links the disappearing of 'ifs' to the emergence of international criminal law as a distinct specialized legal science, a separate sub-discipline constituted by a professionally shared corpus of knowledge - or of 'a substantial body of jurisprudence on genocide, crimes against bumanity, war

* Associate Professor, iCourts - Centre of Excellence for International Courts, Faculty of Law, University of Copenhagen, jvhh@jur.ku.dk.

† Associate Professor, iCourts - Centre of Excellence for International Courts, Faculty of Law, University of Copenhagen, anne.lise.kjer@jur.ku.dk. This research is funded by the Danish National Research Foundation Grant No. DNRFio5 and conducted under the auspices of the Danish National Research Foundation's Centre of Excellence for International Courts (iCourts).

$\ddagger$ We are very grateful to Ioannis Panagis and Troels Kjeldbjerg Jessen, without whose competent assistance this article would not have been written. Thanks are also due to Amanda Potts who commented on and checked the early results of the corpus linguistic pilot study. Furthermore, we are grateful to the editors at the European fournal of Legal Studies, two anonymous reviewers for highly useful and probing comments, which have all helped improve this article, researchers at iCourts, members of the NoLesLaw network, and others with whom we have had enlightening discussions on the project throughout its development. 
crimes, as well as forms of individual and superior responsibility', as the ICTR put it upon its closure.

Keywords: international criminal law, corpus linguistics, epistemology, legal knowledge

\section{TABLE OF CONTENTS}

I. INTRODUCTION. $.5 \mathrm{I}$

II. THE INITIAL FINDING: APPLYING COMPUTER-AsSISTED CORPUS

LINGUISTICS TO THE ICTY CASE LAW 54

I. What is corpus linguistics, and how did we apply it in the pilot study? 54

2. Explaining Corpus Linguistic Surprise: The Difference between Function Words and Content Words .56

3. On Closer Inspection: The Disappearing ifs as a Conditional Connective .............. 58

III. What 'REALLY EXISTS IN THE JURISTIC CONSCIOUSNESS': A GENERIC PHILOSOPHICAL VIEW OF LEGAL KNOWLEDGE 60

I. 'Do Not Make Your Contribution More Informative Than Is Required': Grice's Maxim of Quantity 60

2. The Generic Philosophical View of Legal Knowledge: Hans Kelsen, Foseph Raz and Ronald Dworkin....

3. Disappearing ifs as a Sign of the Coming into Being of International Criminal Law as Tacit Specialized Legal Knowledge

IV. AN ILLUSTRATION: THE TADIĆ DECISION ON JURISDICTION 67

I. 'If the International Tribunal were not validly constituted...': A Challenge to the Foundations

2. From Explicit Decision to 'Silent Prologue to Any Decision at Law' 69

V. A STEADY DECLINE: FOLLOWING UP ON THE INITIAL FINDING . $.7 \mathrm{I}$

I. Expanding and Refining the Analysis of ifs in Recent International Criminal Law (t)

2. The US Supreme Court in comparison 77

VI. From the EXTERnAl Point of VieW: KuHN, BourdieU, AND THE DISAPPEARING IFS

I. The Emerging Paradigm or Doxa of the New Epistemic Community of International Criminal Law

2. 'Law Was Once Introduced Without Reason, and Has Become Reasonable': The Charge of Irrational Relativism. 83

3. Empirical Support for Armchair Philosophers? 86 
With its sister international tribunals and courts, the ICTR has played a pioneering role in the establishment of a credible international criminal justice system, producing a substantial body of jurisprudence on genocide, crimes against humanity, war crimes, as well as forms of individual and superior responsibility.

The ICTR Remembers website ${ }^{1}$

\section{INTRODUCTION}

This paper begins with a mystery. Or at least with a surprising finding. A few years ago, a computer-assisted pilot study of judgements from the International Criminal Tribunal for the former Yugoslavia (ICTY) revealed an unexpected fact about the Tribunal's use of language. ${ }^{2}$ To our surprise, we noticed that at the time the ICTY's Trial Chamber had used the commonplace word if with a statistically significant lower frequency in the latter half of its existence as compared to its earlier years. Comparing judgements from 1996 to 2003 with judgements from 2004 to 2013 revealed that the tribunal had almost halved its use of if, from 86 to 45 ifs per Ioo,ooo words. This development was thrown into sharper relief in a more recent follow-up study which not only brought the corpus up to date but also expanded it to include judgements from both the ICTY's Trial and Appeals Chambers, as well as all judgements from the ICTY's sister tribunal, the International Criminal Tribunal for Rwanda (ICTR). A fine-graining of the comparison revealed that the frequency of the use of ifs across both tribunals had exhibited an almost perfectly steady annual decline from 93 ifs per IOO,OOO words on average in 1996 to 34 on average in 2017.

The question is why the two tribunals would use language in this way. At first glance, it might be tempting to simply dismiss this finding as a freak occurrence or, at best, a trivial puzzle. But this would be a mistake. Bearing in

I 'The ICTR Remembers: 2oth Anniversary of the Rwandan Genocide' $<$ http://www.irmct.org/specials/ictr-remembers/index.html?q=ictrremembers/index.html $>$ accessed 8 November 2018 .

2 This study was carried out in 2014 by Anne Lise Kjær as an integrated part of a larger corpus linguistic research project on international courts. 
mind that language use is not merely an epiphenomenon but should be taken seriously in its own right, this steep and steady decline of $i f$ s is a worthy object of inquiry. As a piece of linguistic behavior, this phenomenon contradicts how we would expect language to behave. There is simply no immediately plausible reason why all the different panels deciding all the different cases brought before the ICTY and the ICTR would collectively choose, as it were, to reduce their use of that particular conjunction by a margin of nearly two thirds. The fact that they did therefore requires explanation, which this contribution attempts to provide.

As we shall see, this is an explanation that takes us from linguistics into the philosophical and sociological study of (legal) knowledge and science, contributing to both these fields in interesting ways. In the most general terms, our explanation links the disappearance of ifs to the emergence of international criminal law as a distinct specialized legal science, a separate sub-discipline constituted by a professionally shared corpus of knowledge or, as the ICTR would express it shortly before its closure, of a 'substantial body of jurisprudence on genocide, crimes against humanity, war crimes, as well as forms of individual and superior responsibility'. ${ }^{3}$

In slightly greater detail, our explanation is twofold. First, reflection on the principles which pragmatics tells us govern cooperative discourse takes us from linguistics to the philosophy of law. Here, mainstream legal philosophers like Hans Kelsen, Joseph Raz and Ronald Dworkin have, each in their own way, defended what we call the generic philosophical view of legal knowledge. In spite of their theoretical differences, Kelsen, Raz, and Dworkin agree on a generic level that legal knowledge and science is philosophically presuppositional in nature. Legal scientific statements about valid law always implicitly or tacitly presuppose the validity of a set of philosophical or theoretical premises on the basis of which the validity of such statements is derived. We argue that a large part of these implicit premises can be reconstructed as conditionals, in which if works as a logical connective (if ..., then ...). This is particularly interesting when we take into account the wider context of the operation of the ICTY and ICTR and especially the fact that international criminal law was virtually nonexistent as a discipline in the mid-I990s, when

3 Cf. n I above. 
the tribunals were established. ${ }^{4}$ In this light, we argue that the disappearing ifs testifies to the gradual coming into being of international criminal law as a specialized kind of legal knowledge and expertise with its own distinct set of tacit philosophical premises constituting the field's 'substantial body of jurisprudence'. At the same time, however, the data seem to point to something beyond the strong internal epistemological focus on the ultimate justifiability of legal knowledge which is characteristic of the generic philosophical approach. The aforementioned patterns in the use of ifs seem also to suggest the gradual emergence of an epistemic community in international criminal law as an empirical institutional fact. The steady decline in the use of ifs testifies to the emergence of a new international criminal law field occupied by an increasingly specialized profession whose members gradually become masters and practitioners of this emerging sub-discipline. This framework gradually allows more conditionals to be tacitly presupposed through technical terminology within expert discourse. This process simultaneously creates new disciplinary boundaries and increasingly seals off the point of view of international criminal law from laypeople and even from other lawyers.

In order to better understand these dynamics, it therefore seems preferable to take a more external perspective, drawing on the sociology of knowledge and of science, rather than an a priori philosophical approach. Here we turn, in particular, to the theories of Thomas Kuhn and Pierre Bourdieu, who have developed certain conceptual tools that are helpful to understand the emergence of the kind of epistemic practice and community that we see in international criminal law. At the same time, however, the theories of these two prominent sociologists can at least be said to invite relativistic and ultimately quite strongly irrationalist readings that appear to be at odds with those found in the philosophy of law. It is therefore also necessary to consider the possible impact of our findings in this context. As we shall see, there is reason to believe that the study of ifs can at least have the effect of moderating and nuancing some of the more relativistic claims of these influential sociological critiques of legal philosophy.

4 The ICTY was established by United Nations Security Council (UNSC) Resolution 827 (25 May 1993). The ICTR was established by UNSC Resolution 955 (8 November 1994). 
We submit that this combination of philosophical and socio-epistemic notions provides the first building blocks for an overall framework that allows for a theoretical explanation of the fact that the tribunals' use of ifs has been changing instead of remaining constant. In order to substantiate this claim, we shall proceed as follows. In section 2 , we recapitulate the initial findings, requiring a brief introduction to the basics of corpus linguistics. In section 3 , we present the generic philosophical view of legal knowledge. In section 4 , we illustrate the general connection between this view and the ifs through a case study of the ICTY's decision on jurisdiction in the Tadic case. In section 5 , we further refine and expand our empirical analysis to include a diachronic study of the case law of the ICTY and the ICTR. In section 6, we turn to the sociology of knowledge and science both to better understand the disappearing ifs and to criticize and nuance these sociological approaches themselves. In section 7 , we summarize our findings and indicate promising avenues for further research.

\section{THE INITIAL FINDING: APPLYING COMPUTER-ASSISTED CORPUS LINGUISTICS TO THE ICTY CASE LAW}

\section{What is corpus linguistics, and how did we apply it in the pilot study?}

As a first step, it is necessary to say a few words about our original findings, which in turn requires a few words more generally about computer-assisted corpus linguistics, through which these findings were made. In corpus linguistics, a corpus is usually defined as '[a] set of machine-readable texts which is deemed an appropriate basis on which to study a specific set of research questions. The set of texts [...] is usually of a size which defies analysis by hand and eye alone within any reasonable timeframe'.$^{5}$ Computers are capable of processing much larger amounts of text and also of 'reading' all these texts in a non-linear way. By submitting large numbers of digitally searchable texts to automated computer analysis, it is therefore possible to make language patterns visible, which no amount of manual analysis would

5 Tony McEnery and Andrew Hardie, Corpus Linguistics: Method, Theory and Practice (Cambridge University Press 2OI2) I-2. 
discover if one were to read the collection of texts as individual, coherent texts. $^{6}$

In corpus linguistic analysis, it is furthermore customary to distinguish between corpus-driven and corpus-based analyses. ${ }^{7}$ Corpus-driven analysis is conducted 'blindly', so to speak, and from the bottom-up. A text corpus is fed to the computer more or less without preconceptions or hypotheses and the digital processing then allows the researcher to open up the corpus by revealing conspicuous linguistic patterns that the researcher may not have expected and may not have searched for. Corpus-based analysis, by contrast, starts with more substantive preconceived notions about what to look for in the corpus, and then uses the computer to check systematically for particular patterns. While this distinction is clear in principle, the two approaches will often mix in research practice, as the findings of corpus-driven analysis tend to give rise to the formation of hypotheses that subsequently require testing in a more targeted corpus-based analysis. ${ }^{8}$

Our study has followed this pattern in so far that it started as a corpus-driven analysis and subsequently switched to a corpus-based approach. More specifically, our study started out as a broad so-called corpus-driven keyword analysis. In corpus linguistics, keywords are words which occur with 'unusual frequency' in a given corpus, i.e. which are statistically significantly over- or underused in the text corpus in question. ${ }^{9}$ This does not mean high frequency in absolute numbers but high relative frequency, i.e. compared to the frequency of the same words in another corpus.

6 Michael Stubbs, 'On Texts, Corpora, and Models of Language' in Michael Hoey et al. (eds), Texts, Discourse and Corpora (Continuum 2007) I30-I3I.

7 The distinction between the two approaches was introduced by Elena TogniniBonelli, Corpus Linguistics at Work (John Benjamins 1997).

8 For a discussion of the two approaches and their interplay, see McEnery and Hardie (n 5) 5-6. See also Amanda Potts and Anne Lise Kjær, 'Constructing Achievement in the International Criminal Tribunal for the Former Yugoslavia: a Corpus-Based Critical Discourse Analysis' (2016) 29(3) International Journal for the Semiotics of Law - Revue Internationale de Sémiotique Juridique 525.

9 Mike Scott, 'PC Analysis of Key Words - and Key Key Words' (1997) 25(2) System 233 , at 236 . 
In our case, the initial corpus-driven keyword analysis was conducted as a pilot study only on the case law of the ICTY, i.e. of the 7I trial judgements delivered in the period from 1996 to 2013 . This corpus was divided into two corpora consisting of the judgements rendered from I996 to $2003(32$ judgements) and from 2004 to 2013 (39 judgements). The aim of the pilot study was to establish whether a change in the tribunal's language use would be detectable over time. The guiding hypothesis was that if a change had in fact occurred, it would show in a simple comparison of the early case law (period $\mathrm{I}$ - pre-2003) and the late case law (period 2 - post-2003). The choice of 2003 as the divide was based on the fact that the two time periods cover approximately the same number of years and judgements. The keyword analysis revealed a number of more or less interesting facts about the 'keyness' of various words in the two corpora. Among the more puzzling was the $48 \%$ drop in the frequency of the word if from the 1996-2003 corpus to the 20042013 corpus (from 86 to 45 ifs per Ioo, ooo words) referred to above.

\section{Explaining Corpus Linguistic Surprise: The Difference between Function Words and Content Words}

From the point of view of corpus linguistics, this finding was quite surprising, more so than, for example, a parallel finding regarding the proper noun Tadic, ${ }^{\text {IO }}$ even though, with a $57 \%$ drop in frequency, the 'keyness' of this latter word was, statistically speaking, more conspicuous. The explanation of why we consider the relatively smaller decline in the use of ifs as 'more surprising' hinges on the general distinction between function words and content words. Function words, such as if, include determiners, pronouns, auxiliary verbs, prepositions, conjunctions, and particles. These are all words which, unlike content words (nouns, lexical verbs, adjectives, and adverbs), have little lexical meaning and do not refer to extralinguistic concepts. Instead, their function is internal to language, serving to express grammatical relationships between words within a sentence. ${ }^{\text {II }}$ They signal the structural relationships that words have to one another and are thus the 'glue' that holds sentences

Io Duško Tadić was the first indictee to have his case brought before the ICTY.

II Michael Stubbs, Words and Phrases. Corpus Studies of Lexical Semantics (Blackwell 200I), 40 , with reference to the original inventor of the distinction between content words and function words, Henry Sweet, A New English Grammar. Logical and Historical (Clarendon I89I) 22. 
together. Unlike content words (such as proper nouns like Tadic, and nouns and phrases like responsibility and joint criminal enterprise), whose presence is strictly contingent upon the content of a text, function words are an omnipresent feature of all language use.

More generally, this is also the reason why when computer-assisted text analysis is applied in social sciences outside of linguistics proper, some researchers treat function words as stop words, i.e. as residual words constituting a kind of 'noise' to be removed from the corpus at the preprocessing stage before the analysis proper. ${ }^{12}$ This is done on the assumption that widely present function words are unrelated to the specific field that the social scientist is interested in. Conversely, to the degree they are included, any conspicuous statistical variations in the use of such words are considered 'merely linguistic' and their study only of interest to linguists.

While disregarding function words may thus be useful for some research purposes, it would be a mistake to do so in all contexts where one's Erkenntnisinteresse ${ }^{13}$ is not 'purely linguistic'. As noted above, the strength of corpus-driven analysis is that it allows the computer to identify striking linguistic patterns that would otherwise remain hidden because they do not fit a researcher's preconceptions or hypotheses. Our finding regarding the use of ifs proves this point. The significant decline in the use of this particular connective constitutes a finding that would have remained hidden if we had proceeded on the assumption that function words are only of linguistic interest. Yet this is also a finding that does not seem to yield itself easily to a purely linguistic explanation, for example by reference to grammar, the specific genre of judgements, or personal style of the individual drafters. First, the time period covered by the corpus was too short for grammatical or genre-specific changes to manifest themselves in this way. Second, the corpus is composed of texts which were to a large extent produced by language users whose first language is not English and who would therefore not be the most likely primary bearers of significant grammatical or other linguistic change.

I2 See e.g. Christopher Lucas et al., 'Computer-Assisted Text Analysis for Comparative Politics' (2015) 23 Political Analysis 254.

${ }_{13}$ The term derives from Habermas and is usually translated with 'knowledge interest' or 'cognitive interest'. 


\section{On Closer Inspection: The Disappearing ifs as a Conditional Connective}

As a first step, it was therefore necessary to take a closer look at the particular role, or roles, which the function word if plays in the ICTY's judgements. In ordinary language, the most widespread use of if is as a logical connective expressing if..., then... conditionals. ${ }^{14}$ In general, we would expect this tendency to be at least the same but presumably stronger with the ifs in our study, since conditionals often constitute a central premise (sometimes called the major premise) in the syllogistic reasoning characteristic of argumentative texts. On closer scrutiny, therefore, it seems plausible that the phenomenon to be explained is, more specifically, the significant drop in the use of if as a conjunction introducing a conditional clause.

Before proceeding, however, we should observe a possible source of error in this preliminary interpretation of the data. More specifically, it is necessary to control for both false positives and false negatives. On the one hand, we should remember that the word if is ambiguous, and that not all instances are conjunctions introducing a conditional clause. For instance, if is also used in the meaning of whether introducing questions (ask if, know if (15 $^{15}$ and it is also used in certain set phrases (if any, if only, if so, and as if). ${ }^{16}$ These uses are not conditional and detecting variations in their frequency would therefore require a different kind of explanation. ${ }^{17}$ On the other hand, not all

I4 'A conditional is a two-clause structure in which one of the clauses is introduced by if (possibly preceded by only, even or except) or by a word or phrase that has a meaning similar to if, only if (e.g. provided) or except if (viz. unless). The only two-clause structures that we do not treat as conditionals are those in which the subordinate clause is introduced by as if or is a subject or object clause introduced by if (which is then equivalent to whether).' Renaat Declerck and Susan Reed, Conditionals: $A$ Comprehensive Empirical Analysis (Topics in English Linguistics [TiEL]) (Mouton de Gruyter 200I) 9.

is E.g. 'That day he was taken for interrogation, a statement that he had given while at Keraterm was read to him, and he was asked if he had anything to add.' Prosecutor v. Duško Tadić a/k/a 'Dule' (Opinion and fudgement) ICTY-94-I-T (7 May 1997) para 248.

${ }^{16}$ E.g. '[S]oldiers on the hangar floor were behaving as if they were supporting a team at a football match.' Prosecutorv. Duško Tadic a/k/a 'Dule' (Opinion and fudgement) ICTY94-I-T (7 May 1997) para 222.

${ }_{17}$ They do exhibit a decline, but their use is insignificant in terms of numbers and cannot account for the general decline that we have detected. According to a SketchEngine search if any declines from $4 \mathrm{I}$ to 27 per million words; if only from 5 to 
conditionals are expressed with the conjunction if. Synonymous expressions include the phrases as long as, on the condition that, provided that, and unless (meaning if not). This means that, all else being equal, we should expect other conditional expressions to co-vary with the ifs.

In general, these considerations call attention to the need to supplement computer-assisted corpus linguistics with in-depth manual analysis. In a corpus the size of ours, we therefore cannot conclusively control for all these factors. However, we believe we can confidently say that, by applying a combination of computer-assisted and manual analysis, we have controlled sufficiently in the present context.

In relation to the false negatives, it seems that the occurrences of these synonymous expressions are quantitatively too insignificant when compared to $i f .^{18}$ Variation in their use can therefore safely be disregarded. In relation to the false positives, we have already mentioned that conditional use of if is generally the most common in ordinary language. In a well-defined corpus, it is in fact possible at least to further support this contention with the use of computers by identifying so-called collocations, i.e. 'the relationship a lexical item has with items that appear with greater than random probability in its (textual) context'. ${ }^{19}$ Using this approach, we found that among the 20 words with which if had the strongest collocations in the ICTY database the word

I per million words; and as if from I9 to 7 per million words in the ICTY Trial Corpus I996-2003 compared to the ICTY Trial Corpus 2004-2013. If so stays stable over time (7 per million words).

I8 As long as is used 2I4 times, provided that $\mathrm{I} 3 \mathrm{I}$ times, and on condition that only $\mathrm{I} 3$ times across time in trial and appeals chamber judgements of the ICTY between 1996-2015. In comparison, if is used 7,899 times. Unless occurs 559 times and exhibits a clearly declining use over time in a preliminary corpus-based study. Please note that this analysis is based on an extended period of time compared to the pilot study. The reason for this is that the control for false negatives was carried out after our corpus had been extended by two additional years.

19 Michael Hoey, Patterns of Lexis in Text (Oxford University Press 1991) 7. In the Glossary to Sketch Engine, the notion of collocation is further described as follows: 'A collocation, e.g. fatal error, typically consists of a node (error) and a collocate (fatal). Collocations can have different strength, e.g. nice house is a weak collocation because both nice and house can combine with lots of other words, on the other hand, the Opera House is a strong collocation because it is very typical for opera to occur next to bouse and, at the same time, opera does not combine with many other words.' 
even was by far the strongest. By comparison, among the set phrases mentioned above only any and only made it to the top 20 (number two and four respectively). In other words, their connection was weaker, in particular since these may include only if (instead of if only), which is a conditional expression. Second, the set phrases (if any, if only, as if) seem to an even higher degree to belong to the category of function words from which it is simply very difficult to imagine why they should change significantly in the way detected. Finally, as we shall discuss below, we have observed in a subsequent, combined manual and computer-based study of the development of a specific doctrinal element (the Joint Criminal Enterprise-doctrine) across the ICTY's practice an even more significant drop specifically in the use of conditional ifs. ${ }^{20}$ This indicates that, if anything, the non-conditional ifs in the corpus have the effect of smoothing out rather than contributing to the drop in the use of ifs. On these grounds, we have found it justified to proceed on the assumption that the decline in ifs primarily reflects a decline in its use as a conditional connective.

\section{WHAT 'REALLY EXISTS IN THE JURISTIC CONSCIOUSNESS': A GENERIC PHILOSOPHICAL VIEW OF LEGAL KNOWLEDGE}

At this point, we found it fruitful to look outside the realm of linguistics to explain our findings. As a first step, we decided to seek insights from the philosophy of law. This allowed us to see how the disappearing ifs testifies to the gradual emergence of international criminal law as a specialized kind of legal knowledge and expertise with its own silent philosophical prologue expressing a distinct set of tacit foundational premises.

\section{I. 'Do Not Make Your Contribution More Informative Than Is Required': Grice's} Maxim of 2uantity

We were led in the direction of philosophy of law by recalling a general feature of language use, which provides an initial indication of why the frequency of if varied so strongly across the two corpora, even if function

${ }^{20}$ See note 6r below. 
words generally do not. This feature was originally identified by the English philosopher of language Herbert Paul Grice. ${ }^{2 \mathrm{I}}$

Grice observed that all contributions to discourse, even apparently monological contributions like judgements, do not merely constitute disconnected remarks. They are, at least to some degree, characterized by being cooperative efforts. When making discursive contributions each speaker 'recognizes, at least to some extent, a common purpose or set of purposes, or at least a mutually accepted direction'. ${ }^{22}$ All else being equal, discourse participants will therefore generally be expected to observe what Grice calls the cooperative principle: 'Make your conversational contribution such as is required at the stage at which it occurs, by the accepted purpose or direction of the talk exchange in which you are engaged'. ${ }^{23}$ Furthermore, Grice suggested spelling out this principle in a set of maxims, one of which is of particular importance for our purposes because it relates to the quantity of information in specific discourse contributions. According to this so-called maxim of quantity:

I. Make your contribution as informative as is required (for the current purposes of the exchange). 2. Do not make your contribution more informative than is required. ${ }^{24}$

This is important in light of the observed conditional character of the disappearing ifs. As noted above, if..., then... conditionals often constitute the central premise (sometimes called the major premise) in the syllogistic reasoning characteristic of argumentative texts like judgements. However, unlike the so-called minor premise of syllogisms, which generally provides concrete information or data specific to the issue at stake in any given argument, the major premise constitutes background knowledge of a more general character. Qua background knowledge, it is widely acknowledged that in actual argumentation the major premise is generally not explicitly spelled

\footnotetext{
21 See generally Herbert Paul Grice, 'Logic and Conversation' in Peter Cole and Jerry L. Morgan (eds), Syntax and Semantics, vol 3 (New York Academic Press I975) 4I.

${ }^{22}$ Ibid 45 .

${ }_{23}$ Ibid.

${ }^{24}$ Ibid.
} 
out if it is assumed to be shared by discourse participants. ${ }^{25}$ For instance, we will usually leave out the uncontroversial conditional 'if the street is wet, then it has been raining' and merely say 'the street is wet, therefore it has been raining'. Conversely, if a conditional premise is assumed to be contested, we will tend to spell it out.

This variation in argumentation practice can be seen precisely as a manifestation of speakers' general obedience to the Gricean maxim of quantity. Attempting to make their arguments as informative as but not more informative than is required, speakers will either leave out or explicitly state the conditional premises of their arguments, depending on whether or not they assume that these conditionals constitute uncontroversial background knowledge shared with their audience. In other words, following Grice we have identified an initial indication of why our pilot study showed a significant drop in the use of ifs: it seems plausible that the jurisprudence of the ICTY generally reflects a development where certain central assumptions of a conditional nature are no longer considered controversial, but rather have become part of a shared background knowledge, and thus no longer need to be explicitly stated.

2. The Generic Philosophical View of Legal Knowledge: Hans Kelsen, Foseph Raz and Ronald Dworkin

In virtue of the epistemic character of these considerations, we were then naturally led in the direction of philosophy of law. More specifically, we decided to look at the tribunal's use of ifs in light of what, for present purposes, we have called the generic philosophical view of legal knowledge. By this notion, we are referring to an understanding of legal knowledge which, at the proper level of abstraction, can be identified across a variety of theories from a number of quite diverse influential legal philosophers.

First, we shall make an approximation of this generic philosophical view through the works of the Austrian legal positivist Hans Kelsen. However, since our motivations are tied to understanding the specific phenomenon at

${ }^{25}$ Cf. e.g. Stephen Toulmin uses a different terminology (where data refers to minor premise and warrant to major premise) but essentially makes the same point: 'data are appealed to explicitly, warrants implicitly.' Stephen Toulmin, The Uses of Argument (2nd edn, Cambridge University Press 2003) 92. 
hand (the declining use of ifs), we shall not attempt a comprehensive exposé of Kelsen's philosophy but approach it in a slightly indirect and somewhat eclectic fashion. More precisely, we shall approach Kelsen's version of the generic philosophical view of legal knowledge via his follower Joseph Raz's discussion of one of the central and most controversial issues in Kelsen's pure theory of law. This is the question of what exactly Kelsen means when, for instance in the General Theory of Law and State, he writes that the 'oughtstatements [of the science of law] have a merely descriptive import; they, as it were, descriptively reproduce the 'ought' of the norms'. ${ }^{26}$ Many have regarded this notion of ought-statements in a descriptive sense as a particularly enigmatic and problematic element in Kelsen's theory. Raz, however, finds the notion both meaningful and rewarding, and he sets out to defend it.

Raz suggests that the 'ought-propositions' of legal science do not generally tell people what they really ought to do. They are, as Raz says, statements from a point of view or detached normative statements. They merely state how things are from the legal point of view. Of the greatest importance in the present context, however, is a related feature of these ought-statements to which Raz draws attention in his further analysis. Thus, he adds that

such statements [cannot] be interpreted as conditionals: 'If you accept this point of view then you should etc.' Rather they assert what is the case from the relevant point of view as if it is valid or on the hypothesis that it is - as Kelsen expresses the point - but without actually endorsing it. ${ }^{27}$

This point is important here because it expresses a general perception of legal knowledge claims that has broad philosophical traction also beyond the specific confines of Kelsen's pure theory of law, which we therefore call the generic philosophical view of legal knowledge. According to this view, the statements of legal science all share three main features. First of all, they have, as already remarked, the general formal feature that they are not conditionals ('if you accept this point of view then you should') but immediately express norms ('you should!'). Secondly, however, they are simultaneously tacitly presuppositional. By this we mean that even if individual scientific legal statements about valid law may not, as they stand, have a conditional character, they nevertheless always implicitly or tacitly presuppose the validity

${ }^{26}$ Hans Kelsen, General Theory of Law and State (Lawbook Exchange 2009) I63.

${ }^{27}$ Ibid I57, emphasis added. 
of a set of such conditional premises on the basis of which their validity is derived. In Kelsen's words:

By formulating the basic norm, we do not introduce into the science of law any new method. We merely make explicit what all jurists, mostly unconsciously, assume. $^{28}$

The legal point of view therefore has a particular content that can be spelled out if pressed. Finally, and corresponding to the idea of one unified point of view, these tacit premises are not merely an arbitrary collection of atomized assumptions each justifying one or more mutually disconnected legal statements. Rather, they are philosophical or theoretical in the sense that they jointly constitute a comprehensive and systematic body of propositions that purport as a whole to provide deep justifications in a consistent and principled way for a whole range of first order legal statements.

As a legal positivist, Kelsen famously holds that these implicit or tacit philosophical premises are constituted by a comprehensive system of positive legal rules. This system of rules is structured hierarchically in such a way that the validity of each individual legal rule can be established only derivatively by regression through a chain of still higher order positive norms that ends ultimately in one so-called 'basic norm'. The tacit (hypothetical) presupposition of the validity of this basic norm constitutes the unique starting point and premise of the entire system of valid law. ${ }^{29}$

However, the claim that legal statements are thus philosophically presuppositional is a generic claim and, in the way we use it, it need not be tied to Kelsen's foundationalist-positivistic hypothesis. On the contrary, we would claim that many legal philosophers seem to hold some version of the generic philosophical view. We shall not attempt to demonstrate this claim exhaustively, but merely demonstrate its presence in the legal philosophy of Ronald Dworkin, who famously occupies a position at the opposite end of the theoretical spectrum. Thus, in spite of the profound differences between Dworkin and Kelsen, we find essentially the same point expressed in the

${ }^{28}$ Ibid Ir6, emphasis added.

${ }^{29}$ Cf. e.g. Kelsen (n 26) II5-II6 and Introduction to the Problems of Legal Theory: $A$ Translation of the First Edition of the Reine Rechtslehre or Pure Theory of Law (Clarendon I992) ch. V. 
work of the former, as demonstrated by the following frequently quoted passage from Dworkin's Law's Empire:

[A]ny judge's opinion is itself a piece of legal philosophy, even when the philosophy is hidden and the visible argument is dominated by citation and lists of facts. Jurisprudence is the general part of adjudication, silent prologue to any decision at law. ${ }^{30}$

As is well known, Dworkin disagrees strongly with Kelsen as to the specific content of this 'silent prologue to any decision at law'. In particular, he rejects Kelsen's assertion of a purely formal basic norm as the unique Archimedian point underlying the entire legal system. Instead, Dworkin maintains that the silent prologue consists of a more coherentist and substantively moral philosophical narrative constituted through a process of constructive interpretation that tries to show the legal system as a whole in its best light and to give the best philosophical justification of this practice. ${ }^{3 \mathrm{I}}$ However, and of key importance here, Dworkin does not dispute but rather affirms the fact that there is a silent philosophical prologue to legal statements. In other words, Dworkin too subscribes to the three tenets characterizing the generic philosophical view of legal knowledge, as presented above.

\section{Disappearing ifs as a Sign of the Coming into Being of International Criminal Law as Tacit Specialized Legal Knowledge}

This is the generic philosophical view of legal knowledge, which we claim is helpful as a first attempt to understand the decline of ifs in the ICTY's and ICTR's case law. This can best be seen if we take a few steps back and remind ourselves of why these two international criminal tribunals constitute such interesting objects of study to begin with. Thus, when The ICTR Remembers website proudly showcases the ad hoc tribunals' role in 'producing a substantial body of jurisprudence on genocide, crimes against humanity, war crimes as well as forms of individual and superior responsibility', ${ }^{32}$ this serves to remind us not merely of the imminent surplus of competent international criminal lawyers seeking work following the closure of the ICTY and the ICTR. It reminds us also of the virtual absence of any such body of

\footnotetext{
${ }^{30}$ Ronald Dworkin, Law's Empire (Hart Publishing I998) 90.

${ }^{31}$ Ibid.

${ }^{32}$ Cf. introductory quote, $\mathrm{n}$ I.
} 
jurisprudence during the mid-9os, when the two tribunals first came into being. At that time, there was simply no commonly agreed upon 'body of jurisprudence' on international crimes and forms of responsibility, not to mention on the fundamental legality and jurisdiction of these new legal institutions. This means that there simply was no international criminal law point of view readily available for the ICTY and ICTR judges to adopt. Apart from the rudimentary remnants of the Nuremberg and Tokyo tribunals and a statute based on one Security Council resolution, the whole 'body of jurisprudence', and thus in effect the entire international criminal law point of view, had to be constructed virtually from scratch.

In light of this historical context, and mindful of Raz's suggestion that legal statements from a point of view '[cannot] be interpreted as conditionals', as explained above, our tentative explanation for the significant decline in the use of ifs in the ICTY judgements was that this finding could be evidence of the coming into being of the international criminal law point of view. In other words, the decreased frequency of ifs could testify to the actual approximation, taking place directly among judges at the tribunals (and plausibly also indirectly among actors in the international criminal legal field more broadly), to something like the generic philosophical view of legal knowledge, i.e. to the notions i) that expressions of doctrinal knowledge specifically about international criminal law are unconditional; ii) that they are implicitly or tacitly presuppositional; and iii) that this presuppositionality is philosophical or theoretical. At the same time, however, this implies also that international criminal law did not conform to the generic view from the beginning. On the contrary, the relatively higher frequency of ifs in the early corpus evidences a significantly greater tendency of the ICTY toward being explicit about the conditionals underlying its statements about the content of valid international criminal law on different issues. Put differently, our hypothesis is that the changes in the relative use of ifs are caused by the coming into being in international criminal law of an epistemic community where the members come to share a point of viere, to a certain degree, which renders it possible for them to make explicitly unconditional, yet tacitly philosophically presuppositional doctrinal normative statements from this point of view. 


\section{AN ILLUSTRATION: THE TADIĆ DECISION ON JURISDICTION}

\section{I. 'If the International Tribunal were not validly constituted...': A Challenge to the Foundations}

Admittedly, this may sound somewhat abstract. Perhaps we can approach a clearer understanding of the general role of the ifs in relation to the creation of the international criminal law point of view via a concrete example. This example is taken from the abovementioned case against Duško Tadić. We shall not, however, be looking at the ICTY's judgement in the Tadic case itself, which was part of the pre-2003 corpus in the pilot study. Instead, we start outside the corpus of judgements by looking at one of the tribunal's preliminary decisions, probably its most seminal one, namely its decision on the defense motion on jurisdiction. ${ }^{33}$ As we shall see, there is an advantage in starting outside the corpus used in the pilot study.

Tadić was the first to be tried before an international war crimes tribunal created by the international community. By the time of the trial in 1995 , the ICTY remained a hugely controversial institution in spite of having been established by a unanimous UN Security Council Resolution. ${ }^{34}$ It was therefore not completely surprising that Tadić's first legal move was to file a preliminary motion on jurisdiction, in the broadest sense of that word. Thus, Tadic challenged the tribunal's very right to try him in the first place by challenging the fundamental legality of the entire ICTY as an institution. This meant that before even contemplating making the most modest contribution to 'the substantial body of jurisprudence on international crimes and modes of responsibility', the ICTY had to justify its very existence and its right to try individuals.

As is well known, the tribunal dismissed the defense motion and asserted its jurisdiction, thus allowing the trial against Tadić to commence. ${ }^{35}$ At its most basic, therefore, the conclusion of the tribunal's decision amounted to the

33 The Trial Chamber issued its decision on Io August 1995. Tadić immediately appealed and the Appeals Chamber issued its decision on 2 October 1995. The trial commenced on 7 May 1996.

34 UN Security Council Resolution 827 adopted 25 May 1993.

35 This formulation needs qualification. Cf. immediately below on the differences between the Trial Chamber's and the Appeal Chamber's decisions. 
following normative statement: 'Yes, we have the right to try Tadić'. In isolation, this is indeed a legal statement in Raz's sense, i.e. an unconditional statement made from a point of view. Crucially, however, the tribunal said more than that. Taken as a whole, the tribunal's decision was not silent about, but rather explicitly stated all the presuppositions underlying this normative conclusion. In this sense, the tribunal's decision perfectly constituted Dworkin's philosophical 'prologue to any decision at law'; it stated what according to Kelsen 'all jurists assume'. In philosophical terms, the decision constituted the conditions of possibility for any future judgement by providing a fully-fledged argument for the fundamental legality of the institution and its right to prosecute individuals.

From the point of view of corpus linguistics, looking at both the Trial and the Appeals Chambers' decisions on jurisdiction, Tadic contains a very high frequency of ifs with IOI occurrences per IOO, ooo words, thus confirming the general picture of the early ICTY case law. ${ }^{36}$ Of particular interest here, however, is that several arguments in the tribunal's reasoning contained conditionals of the form if ..., then .... This is exemplified in the following passage in which the Appeals Chamber recapitulates the stakes of Tadić's challenge: 'In sum, if the International Tribunal were not validly constituted, it would lack the legitimate power to decide in time or space or over any person or subject-matter'. ${ }^{37}$ As a whole, the reasoning thus constructed a

${ }^{36}$ Tadić Case (Decision on the Defence Motion on Jurisdiction) (Io Aug 1995), and Tadić Case (Decision on the Defence Motion for Interlocutory Appeal on Jurisdiction) (2 October 1995).

37 Tadic Case (Decision on the Defence Motion for Interlocutory Appeal on Jurisdiction) (2 October 1995), para I2, emphasis added. Other examples from the Appeals Chamber's decision, cf. e.g. paras 30 and 36 . A few characteristic examples from the Trial Chamber's decision include:

'It is a matter of logic that if the Security Council acted arbitrarily or for an ulterior purpose it would be acting outside the purview of the powers delegated to it in the Charter.' (para I5)

'If the General Assembly has the authority to create a subsidiary judicial body, then surely the Security Council can create such a body in the exercise of its wide discretion to act under Chapter VII.' (para 35)

'If the Security Council in its informed wisdom, acting well within its powers pursuant to Article 39 and 4I under Chapter VII of the Charter, creates the International Tribunal to share the burden of bringing perpetrators of universal 
hierarchy of norms which, legal technicalities aside, can be reconstructed in the following way: i) the ICTY has the right to try Tadic (and other indictees) if the ICTY has primacy and the case is within subject-matter jurisdiction; ii) the ICTY has primacy and the case is within subject-matter jurisdiction if the ICTY statute is valid; iii) the ICTY statute is valid if UN Security Council Resolution 827 is valid; iv) Resolution 827 is valid if it is made in accordance with Chapter VII of the UN Charter. ${ }^{38}$

\section{From Explicit Decision to 'Silent Prologue to Any Decision at Law'}

On this reconstruction, the reasoning of the court can be depicted in the following way:

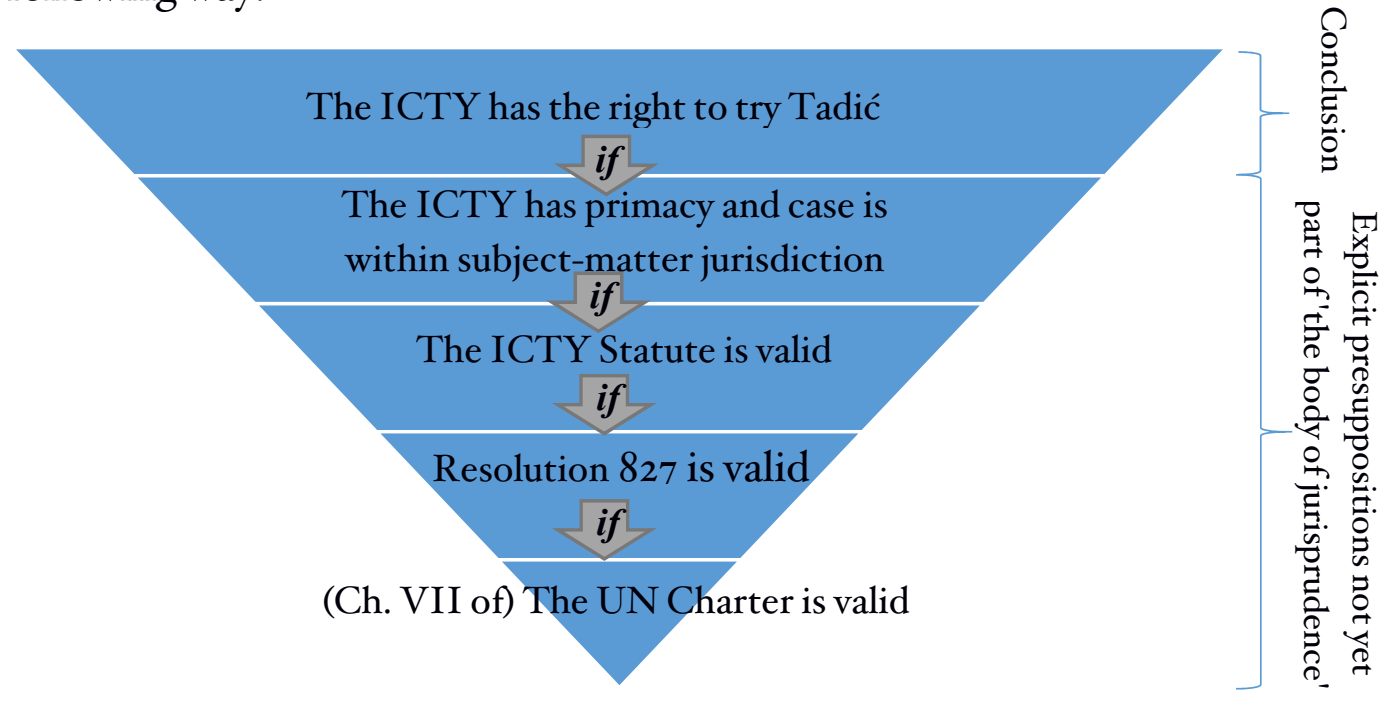

Figure I. Reconstruction of the ICTY's reasoning in defense of its right to try Tadic

From this reconstruction, we observe two things. First, the reasoning of the ICTY in its very first decision closely resembles the philosophical presuppositions underlying every legal statement according to the generic view described above. In order to match these perfectly, the reasoning needed only to have been expanded slightly to include a final assumption regarding the validity of the UN Charter that this follows either if, following Kelsen, we presuppose that pacta sunt servanda, which in turn is valid if we

crimes to justice, the Trial Chamber can see no invasion into a State's jurisdiction because, as it has been rightly argued on behalf of the Prosecutor, they were never crimes within the exclusive jurisdiction of any individual State.' (para 44)

${ }^{38}$ We emphasize that the actual reasoning of the court is far richer and include many more conditionals at each step of this norm-hierarchy. 
presuppose the basic norm of international law that 'the States ought to behave as they have customarily behaved', ${ }^{39}$ or if, following Dworkin, this interpretation shows the system of international criminal law 'in its best light' $4^{\circ}$

Secondly, we see how, following Dworkin more closely, this philosophical prologue is silent (or, following Kelsen, the assumption mostly unconscious) precisely in virtue of being a preliminary ruling and thus deliberately not intended as an explicit part of the Tadic judgement or of any other future judgement issued by the tribunal. In fact, in the case of the Trial Chamber, the decision can be said to be silent also in a wider sense. Although the Trial Chamber also argued in favor of the legality of the creation of the tribunal, and did so on largely the same grounds as the Appeals Chamber, the former, in contrast to the latter, decided that it was not legally competent to make a formal ruling on the motion on jurisdiction. The Trial Chamber therefore emphasized that its argument for jurisdiction was only 'a comment', which it felt obliged to make in light of the 'importance that a body that judges the criminality of [human] behavior should be viewed as legitimate.' In this way, the Trial Chamber's argument was a silent prologue also in the wider sense that even when pronounced it was legally silent.

What is crucial, however, is that unlike the generic philosophical view, the court manifestly did not stay silent about this 'prologue to its decision at law' in this very first decision; the assumption did not remain 'mostly unconscious'. On the contrary, before becoming 'silent'/'unconscious' it had to be stated explicitly. Only when this groundwork had been laid out - and this is particularly important with a view to understanding how logical connectives like if can disappear - this ceased to be necessary. Only then could the conditionals underlying this claim become tacit presuppositions and the court could henceforth simply assume - 'unconsciously' - for all future cases that it had the right to try indictees. ${ }^{4 \mathrm{I}}$ This gives the following picture post-Tadic:

39 Kelsen (n 26) 369 .

$4^{\circ 0}$ Dworkin (n 30) 90.

${ }^{4}$ If on a rare occasion the conclusion should be challenged, it need not even restate the tacit presuppositions but can refer to the previous statement of them. This happened on a few occasions in the ICTY practice. 


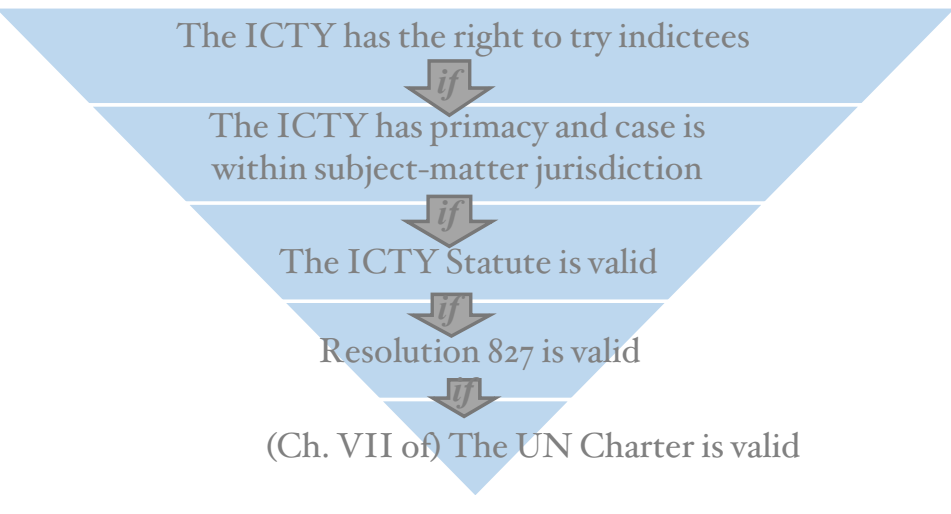

'The silent prologue to any decision at law'/'what all jurists, mostly unconsciously, assume', i.e. the tacit presuppositions that post-Tadic have become part of the body of jurisprudence

Figure 2. Reconstruction of the ICTY's point of view postTadić decision

\section{A STEADY DECLINE: FOLLOWING UP ON THE INITIAL FINDING}

\section{Expanding and Refining the Analysis of ifs in Recent International Criminal Law}

This brief account of the ICTY's decision on jurisdiction in the Tadic case serves to illustrate the fundamental connection between 'disappearing' ifs and the development of a legal point of view according to the generic philosophical view of legal knowledge. At the same time, however, the example does not explain the specific finding in the pilot study, i.e. the conspicuous drop in use of ifs between the pre- and the post-2003 corpora. On the contrary, it illustrates how conditionals had already disappeared before the first judgement was issued by the ICTY.

A more nuanced explanation is thus required. In terms of the generic philosophical view, what the decision on jurisdiction tells us is how the most fundamental elements of the international criminal law point of viere were already in place before the first judgement. Therefore, the observed drop in the tribunal's use of ifs over time cannot strictly speaking be taken to signify the coming into being of that point of view. Instead, it must more accurately be taken as a sign of the transformation of the international criminal law point of view from an embryonic form and into a more mature and comprehensive one. Hypothetically, therefore, the observed drop in the use of ifs must be tied to the transformation of the silent prologue of the international criminal law point of view, from a point where it merely included the assertion of the ICTY's jurisdiction to a point, upon its closure, where it included 'a 
substantial body of jurisprudence on genocide, crimes against humanity, war crimes, as well as forms of individual and superior responsibility.'

This implies that the legal point of view has undergone consistent development, presumably through a more gradual process throughout the tribunal's existence. However, adequately tracking and documenting such a process requires a more refined dataset. As the next step, we therefore conducted a number of more targeted computerized analyses, supplementing these with close manual reading where computer-based analysis could no longer assist.

First, it was necessary to perform a much more fine-grained analysis of ifs in the corpus over time. The division into a pre- and a post-2003 corpus is simply too crude if the aim is to establish a connection between the decrease in the use of ifs and the establishment in the field of international criminal law of something like the generic philosophical view. We therefore first had to make sure that the decrease could not simply be ascribed to the periodization that we had made, for example as a result of an anomalous overuse of if in one particular year. In order to exclude this possibility, we divided the entire corpus of the ICTY into sub-corpora, grouping judgements by year from I996 to 2017 .

Second, it was necessary to make sure that the detected development was not a matter of idiosyncrasy in the way the ICTY Trial Chamber judges used language. We therefore expanded the corpora so as to include judgements from both the ICTY's Trial and Appeals Chambers, as well as all judgements from the ICTY's sister tribunal, the ICTR. As noted above, the ICTR came into existence under relevantly similar conditions and its judgements span almost the same time period (1998-2015). The results of an analysis of the relative frequency of ifs per IOO,OOO words per year across these four chambers are shown in the figures below. 


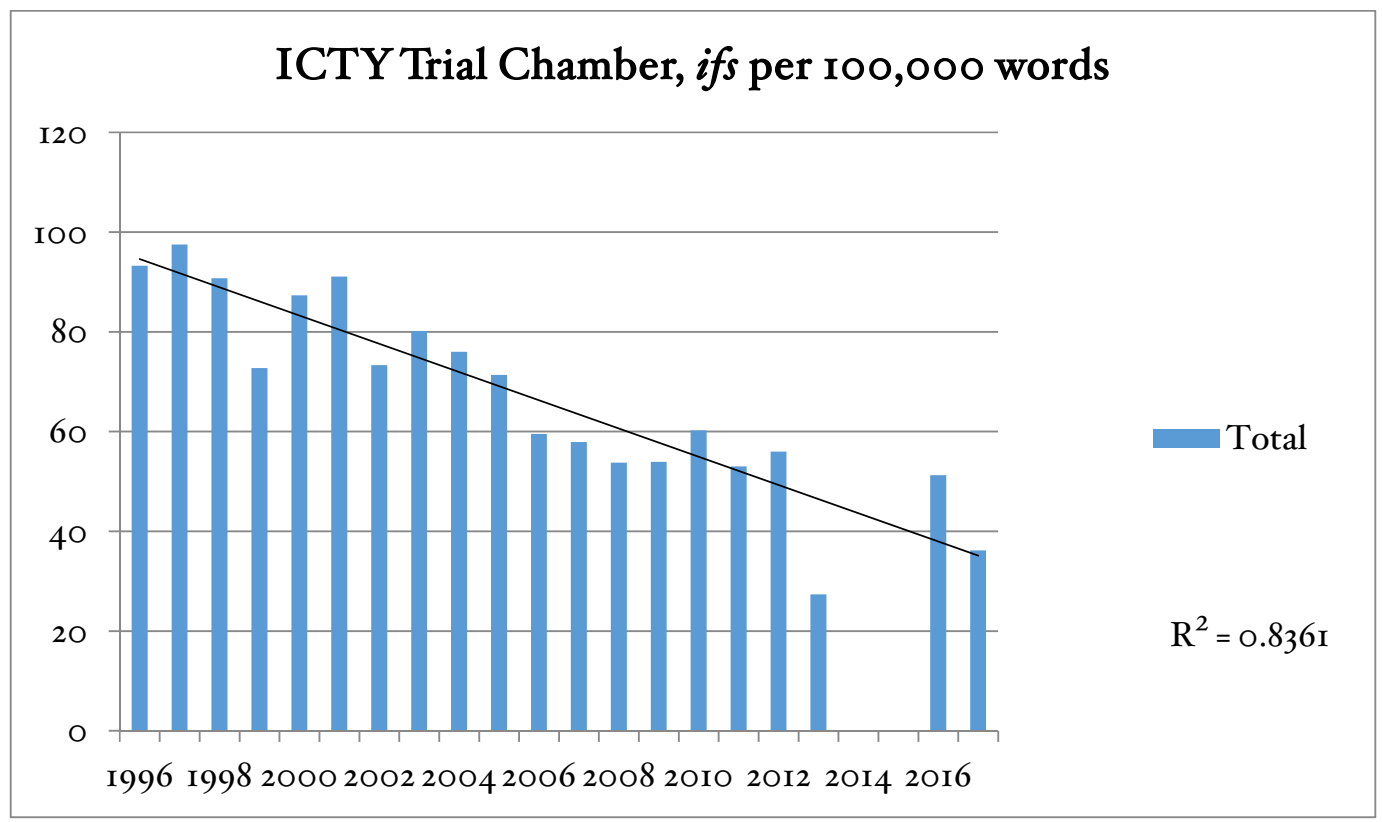

Figure 3. Relative frequency of ifs in ICTY Trial Chamber judgements 1996-20I7

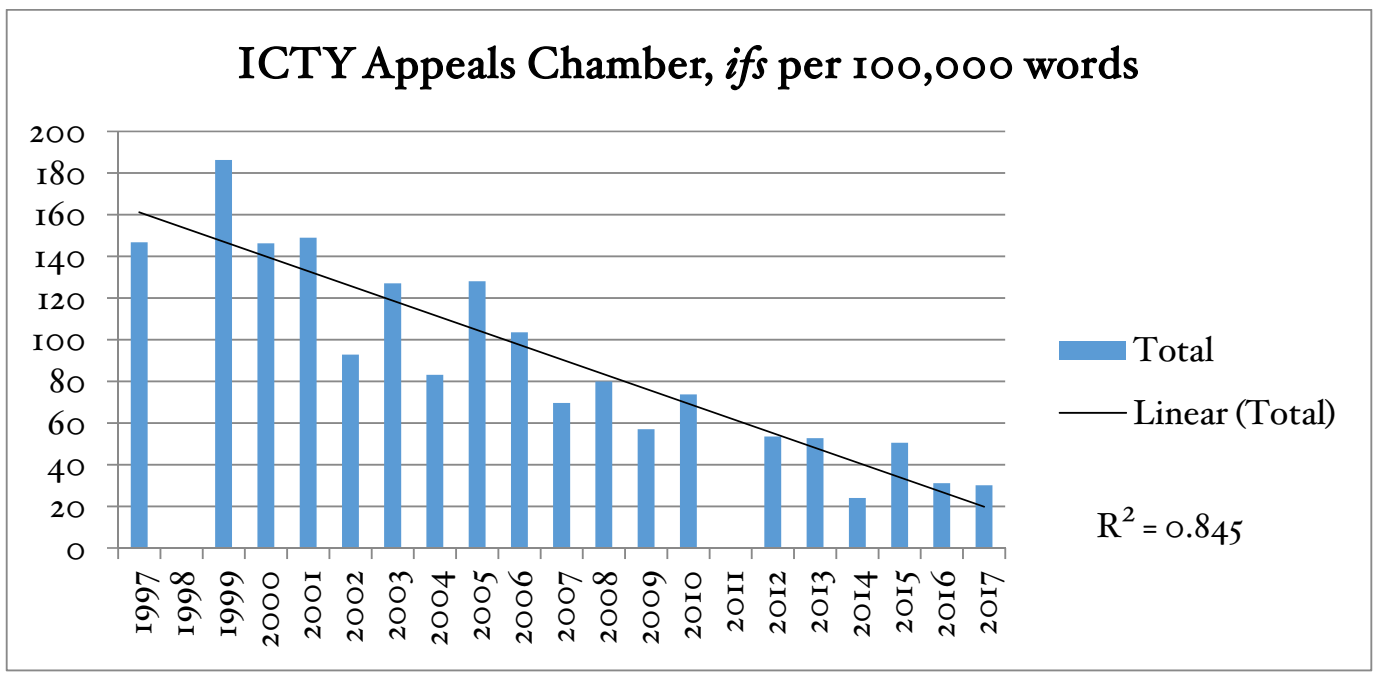

Figure 4. Relative frequency of ifs in ICTY Appeals Chamber judgements 1997-2017 


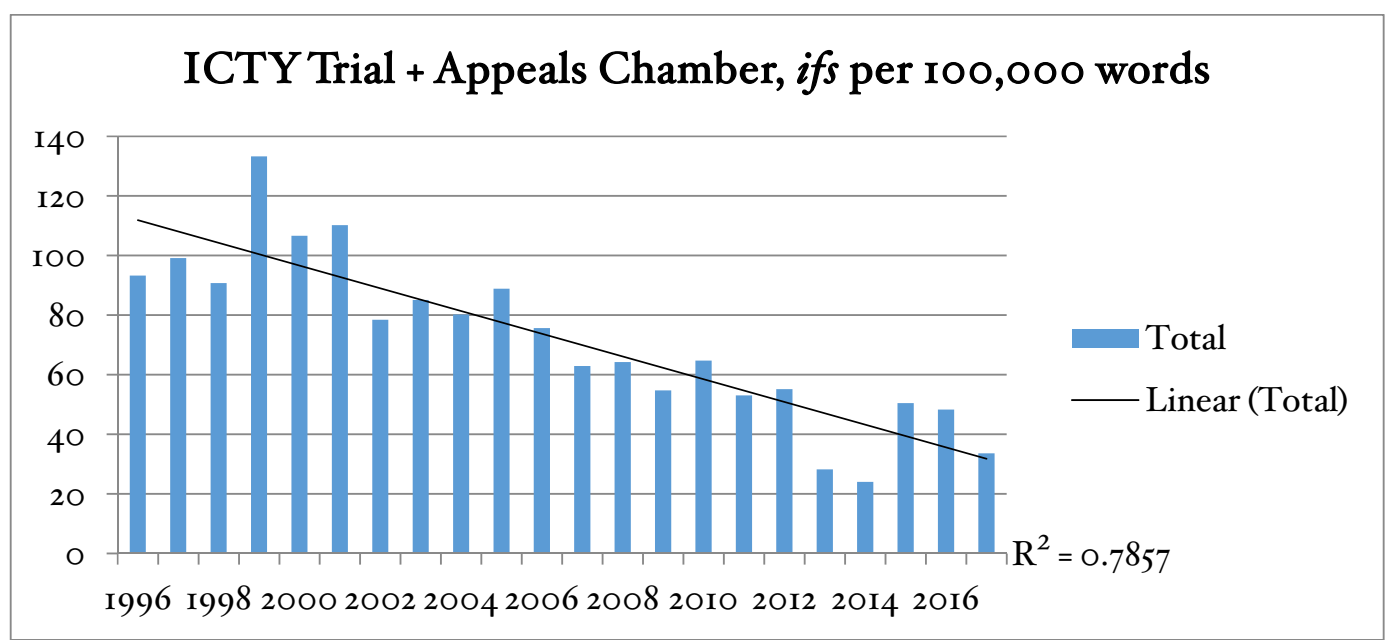

Figure 5. Relative frequency of ifs in ICTY Trial + Appeals Chamber judgements I996-20I7

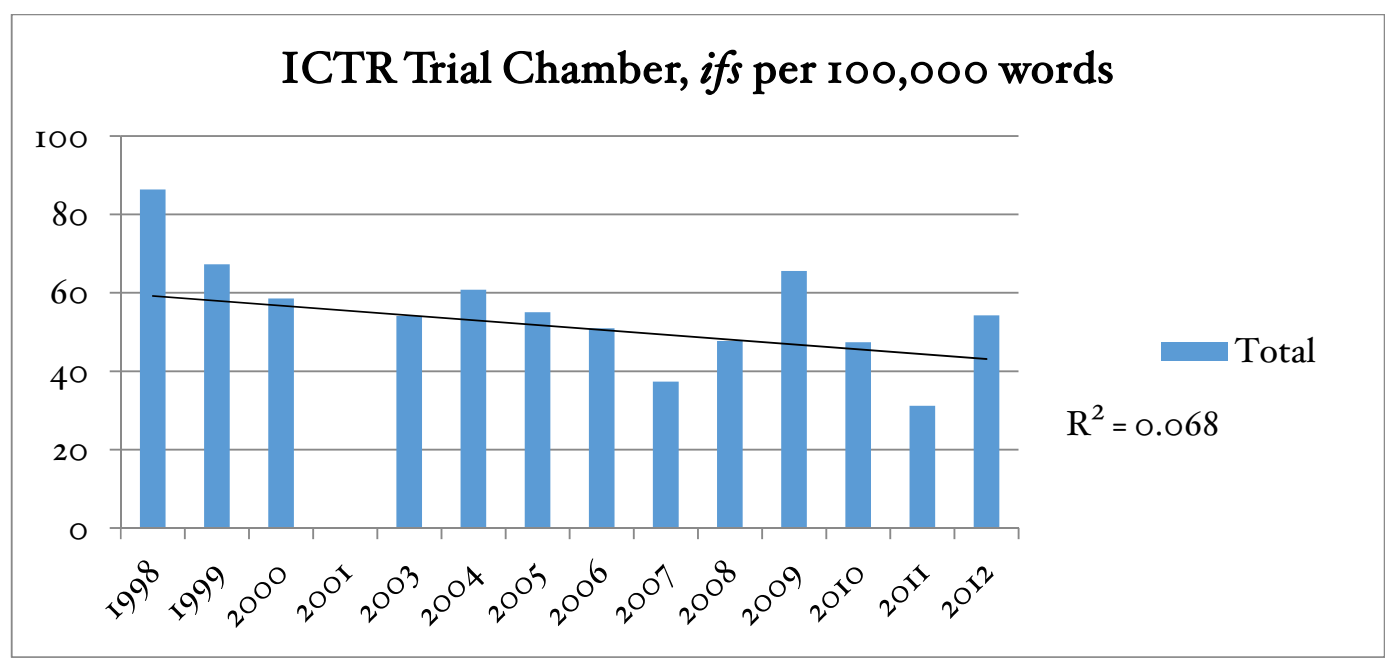

Figure 6. Relative frequency of ifs in ICTR Trial Chamber judgements $1998-2012$ 


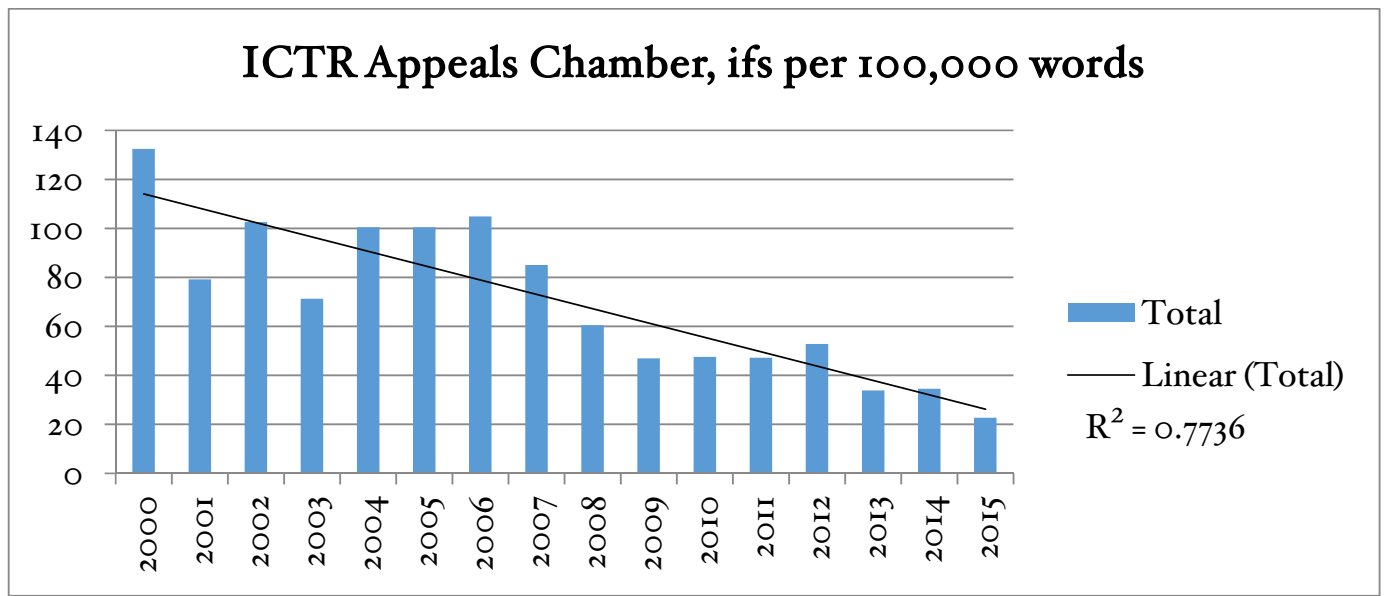

Figure 7. Relative frequency of ifs in ICTR Appeals Chamber judgements 2000-2015

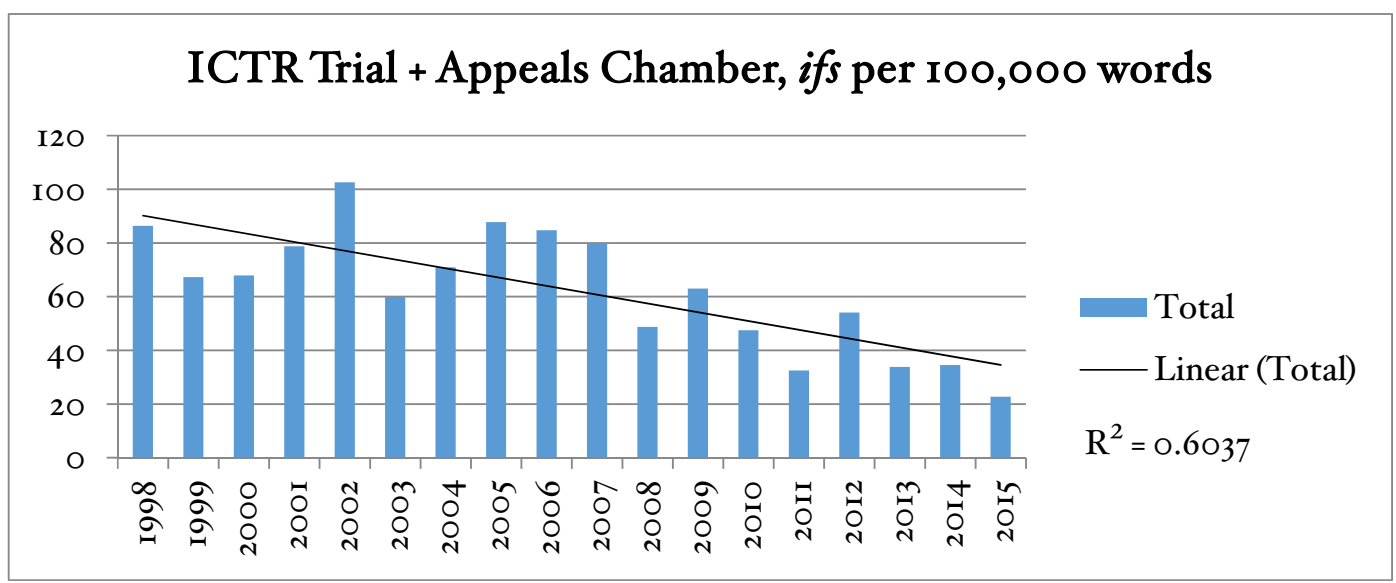

Figure 8. Relative frequency of ifs in ICTR Trial + Appeals Chamber judgements 1998-2015

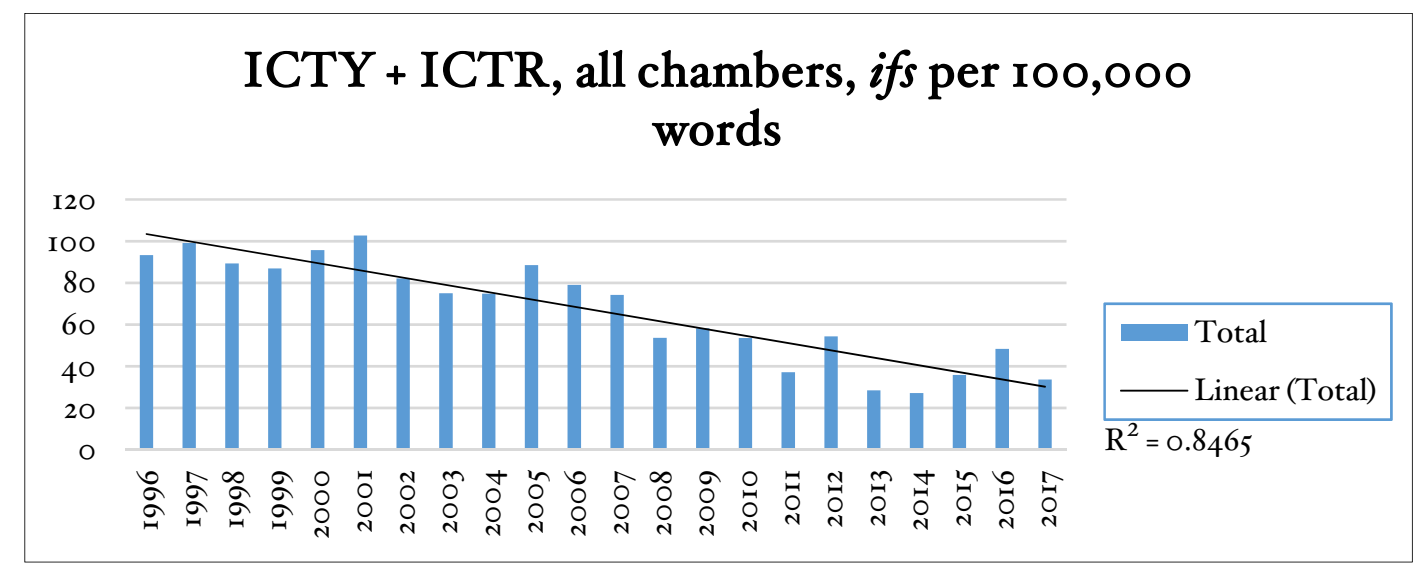

Figure 9. Relative frequency of ifs in ICTY + ICTR, all chambers judgements 
Some variation notwithstanding, the general picture that emerges from these charts is very consistent and arguably provides further support for our hypothesis. As indicated by the trendlines, all the datasets exhibit a declining tendency in relative frequency of ifs, with values generally falling across chambers and tribunals from around Ioo occurrences per I00,000 words in the earliest judgements to around 50 in the latest. The trendlines of the ICTY Trial and Appeals Chambers and the ICTR Appeals Chamber in particular show a very good fit with the data, with R-squared values of $0.836 \mathrm{I}$, 0.8465 , and 0.7735 respectively..$^{2}$ By comparison, the picture of the ICTR Trial Chamber is somewhat murkier, with an R-squared value of only 0.068 , but still indicates a decreasing trend. Bearing in mind the vagaries and contingencies of language use, the general fit of the falling linear trendlines is arguably as good as one could possibly expect of a corpus of this size and kind. This is especially emphasized in figures 5 and 8 , where we have added the values of the Trial and Appeals Chambers (0.7857 and 0.6037 respectively), and in figure 9, which combines the data for both chambers of both tribunals (o.8465).

The overall picture that emerges from the case law is therefore remarkably consistent with our hypothesis and provides little support for other possible interpretations of the initial data. If we leave it at that, however, there is a danger of selecting on the dependent variable, in the sense that we have been looking only at corpora from tribunals whose case law coincides with the coming into being of the corresponding specialized legal discipline. So far, we do not know whether the disappearance of ifs refers to a more general phenomenon in legal use of language. If we are correct, this should not be the case. Assuming we are right that the gradual disappearance of ifs is connected with and provides evidence of the coming into being of a distinct international criminal law point of view in the sense described above, then we should expect not to be able to detect a similar linguistic development in the case law of courts which are long established and therefore make statements

${ }^{42} \mathrm{R}$-squared value is a statistical measure of how close the collected data are to the trend line. R-squared values fall between o and I, and, in general, the higher the R-squared value the closer the fit. Although a rule of thumb suggests that $\mathrm{R}$-squared values above 0.7 indicate a good fit there is strictly speaking no universal measure what is required for a 'good fit'. However, the measured values in this study are clearly very high, suggesting a very strong trend. 
about law from already well-developed and commonly accepted points of view.

\section{The US Supreme Court in comparison}

It of course falls outside the scope of one study to control systematically and exhaustively for this possibility. However, a study of one carefully selected court can still be useful. Depending on the outcome, such a study can serve either to rule out the possibility that we are seeing a development that is exclusively characteristic of the field of international criminal law or, conversely, it can serve to rule out the possibility that what we are seeing is some sort of universal tendency in law. For these purposes, we have chosen to look closer at the case law of the US Supreme Court, which by the time the ad hoc tribunals were established had been issuing judgements for centuries. ${ }^{43}$ This simultaneously provided an opportunity to look further back in time to the decades preceding the establishment of the ICTY and the ICTR. The scope of the analysis was expanded to include the period between I935 and 20I7. The results are shown in figure io, below.

${ }^{43}$ As already mentioned, we have chosen the US Supreme Court instead of, for example, an international court in order to avoid selecting on the dependent variable. In order to verify our hypothesis that the declining use of ifs is connected to the establishment of a specific legal point of view, a 'body of jurisprudence', we needed to control our findings against a court that has a very rich and long case law prehistory going far back before the case law of the ICTY and the ICTR. However, most international courts have developed most of their case law within the last two-four decades. If we are right, they would therefore be likely to display much the same development during that time. The only international court that does not fall prey to this is the International Court of Justice (ICJ). Unfortunately, using the ICJ would leave us with a problem of small numbers, as the Court generally passes much shorter and much fewer judgements - only I29 judgements in total since 1948 compared to the 280 ICTY and ICTR-judgements rendered since 1996. 


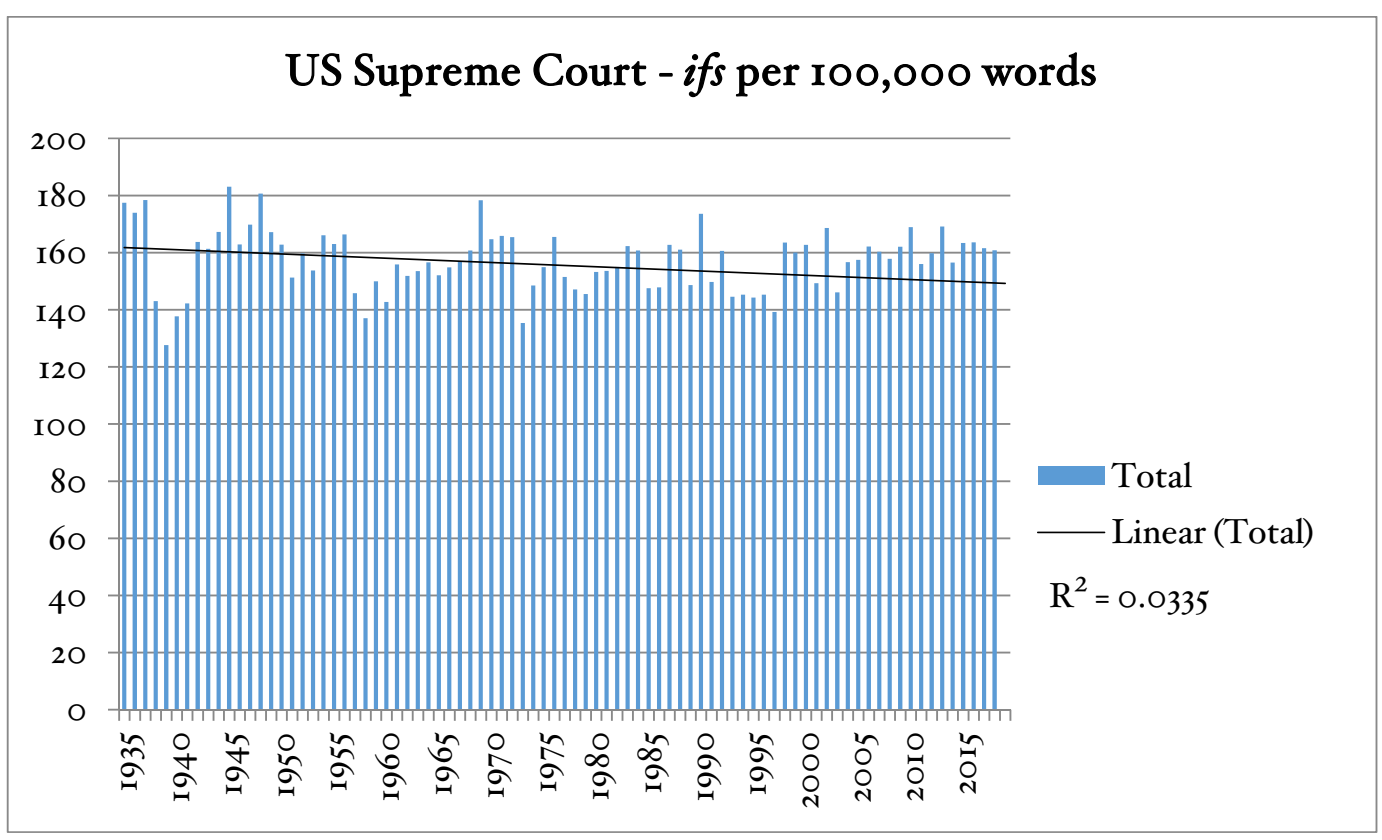

Figure 10. Relative frequency of ifs in US Supreme Court opinions 1935-2017

The general picture that emerges from these data is clearly different. First, even across a time span of more than 80 years we see much more limited fluctuations, with the lowest frequency only $30 \%$ lower than the highest frequency (as compared with the $74 \%$ difference between the highest and the lowest frequencies across the two decades of ICTY and ICTR case law). Second, unlike the quite steep and steady decline in the ad boc tribunals, the US Supreme Court's frequency values oscillate much less consistently, resulting in a very weak declining tendency, with a very low $\mathrm{R}$-squared value (0.0335 compared with 0.8465 for the ad hocs). The general picture is one of random oscillations around an equilibrium, as one would expect from a court that has firmly established its legal point of view in the course of its more than 200 year-long history.

Interestingly, however, while the US Supreme Court data can thus generally be said to support our hypothesis, the data also show one thing that at least superficially seems to contradict it. Across the entire time span, the US Supreme Court uses ifs with a frequency that is almost twice as high as the highest frequency used initially by the ICTY and the ICTR. If the observed decline in the frequency of ifs in the ad boc tribunals' judgements to values around 34 per I0о, oоo words is meant to indicate an approximation toward the generic philosophical view, then it would seem reasonable to claim that a roughly constant level of ifs at a much higher level would indicate the exact 
opposite, i.e. an absence of the generic philosophical view. However, a preliminary study indicates that if we expand the analysis of US Supreme Court Opinions to cover all years from the origins of the Court, then the relative frequency of if over time exhibits a gradual decline just as evidenced in the case of the ICTY / ICTR. 44 Therefore, the higher frequency of ifs in the Supreme Court Opinions must be explained by other factors, most likely by divergent genre conventions, i.e. differences between the ways in which US judges and the international criminal law community write judgements. Thus, as mentioned above, our initial formulation of the hypothesis is somewhat crude and in need of further refinement and nuance. We submit that the observation of this higher level of ifs in the US Supreme Court motivates a(nother) refinement of the hypothesis rather than a rejection of it.

\section{FROM THE EXTERNAL POINT OF VIEW: KUHN, BOURDIEU, AND THE DISAPPEARING IFS}

\section{The Emerging Paradigm or Doxa of the New Epistemic Community of International Criminal Law}

It generally seems that these data strongly support our hypothesis that the development in the two tribunals' use of ifs is tied to the generic philosophical view of legal knowledge and that they document the gradual coming into being and further consolidation of an increasingly comprehensive and rich international criminal law point of view. In this sense, the analysis supports what Dworkin has described as the process of law 'working itself pure'. ${ }^{45}$ At the same time, however, the data seem to suggest something more, something which is not directly touched upon by the philosophical approach with its strong internal epistemological focus on the ultimate justifiability of legal knowledge. More specifically, the data seem to describe also the gradual emergence of an epistemic community in international criminal law as an empirical institutional fact. This additional aspect might be better comprehended if we adopt an external perspective,

\footnotetext{
44 We hope in a later study to be able to provide a full analysis of the ifs in the entire US Supreme Court case law from the beginning of its existence.

${ }_{45}$ Ronald Dworkin, 'Law's Ambition for Itself' (1985) 7I Virginia Law Review 173.
} 
applying notions and concepts from the sociology of knowledge and science, as developed by Thomas Kuhn and Pierre Bourdieu.

This additional perspective is further necessary in light of the fact that the theories of these two prominent sociologists do not merely address topics other than the philosophy of law, but also overlap and to some degree stand in opposition to it, presenting a challenge to the philosophical account of knowledge and science. It is therefore necessary to also consider the possible impact of our findings on this contrasting view. As we shall see, there is reason to believe that our findings might assist in nuancing some of the main claims of these influential sociological critiques of legal philosophy.

Looking closer at the steady gradual decline in the use of conditional ifs, this pattern testifies to the emergence of a new field occupied by members of an increasingly specialized profession of international criminal lawyers who gradually become masters and practitioners of an emerging sub-discipline, sharing a body of highly specialized expert knowledge. At the same time, this is a process that can be said to create new disciplinary boundaries and, increasingly, to seal off the international criminal law point of view from those outside the discipline, not only laypeople but also lawyers specialized in other disciplines, such as national criminal law.

In the general context of international law, the term autonomization has been put forward to describe the gradual development in various international legal fields of a body of legal knowledge marked by common references, concepts, and principles and by methods of interpretation and of adjudication specific to international courts. ${ }^{46}$ This notion can further be explored through key concepts developed in the sociology of knowledge and science, notably Pierre Bourdieu's 'doxa' and Thomas Kuhn's 'paradigm'.

Bourdieu defines the concept of doxa as follows:

All those who are involved in the fields, whether champions of orthodoxy or heterodoxy, share a tacit adherence to the same doxa which makes their competition possible and assigns its limits (the heretic remains a believer who preaches a return to purer forms of the faith). It effectively forbids

${ }^{46}$ Cf. Mikael R. Madsen, 'From Cold War Instrument to Supreme European Court: The European Court of Human Rights at the Crossroads of International and National Law and Politics' (2009) 32(I) Law and Social Inquiry I37-I59. 
questioning of the principles of belief, which would threaten the very existence of the field. Participants have ultimately no answer to questions about the reasons for their membership in the game, their visceral commitment to it; and the principles which may be invoked in such a case are merely post festum rationalizations intended to justify an unjustifiable investment, to themselves as much as to others. ${ }^{47}$

This concept has been invoked, for example, by Mikael Rask Madsen in his analysis of autonomization in the emerging field of human rights. ${ }^{4}$ Along similar lines, Frédéric Mégret sees in international criminal law the development and consolidation of doxa across the last couple of decades as the possibility-condition for the emergence of this new (sub)field:

[I]nternational criminal justice relies on a series of shared 'common places' about its origins and finality [...]. For all the surface disagreement, part of the discipline's resilience can be explained by the existence of a deeply shared doxa $\left[\ldots . . .{ }^{49}\right.$

Turning to Thomas Kuhn, the notion of a 'paradigm' can be explained in close relation to so-called 'normal science' (the science that takes place between the unusual moments of scientific revolutions):

47 Pierre Bourdieu, Pascalian Meditations (Polity Press 2000) 86. Cf. also notably Pierre Bourdieu, Outline of a Theory of Practice (Cambridge University Press 1977) and Cécile Deer, 'Doxa' in Michael Grenfell (ed), Pierre Bourdieu: Key Concepts (Cambridge University Press 20I3) II9-I3O.

$4^{8}$ '[The Bourdieusian] approach [...] seeks an analysis of the gradual emergence of a more structured field of human rights on the basis of the practices of a series of agents and institutions, which, during different historical stages, have helped define this social space and its overriding logics. This becomes an analysis of the different nomos and illusio and eventual doxa of the field and the ways in which this influenced the logic of practice of the agents.' Mikael R. Madsen, 'Reflexivity and the Construction of the International Object: The Case of Human Rights' (2OII) 5(3) International Political Sociology 265. Similarly, Jean D'Aspremont uses Bourdieu in his general analysis of international law as a belief system - although he avoids doxa and focuses instead on Bourdieu's closely related notion of miscognition, Jean D'Aspremont, International Law as a Belief System (Cambridge University Press 2017), especially ch. I.

${ }^{49}$ Mégret, 'International Criminal Justice as a Juridical Field' [2016] Vol. XIII Champ pénal/Penal field <https://journals.openedition.org/champpenal/9284 $>$ accessed 8 November 2018. 
[N]ormal science can succeed in making progress only if there is a strong commitment by the relevant scientific community to their shared theoretical beliefs, values, instruments and techniques, and even metaphysics. This constellation of shared commitments Kuhn at one point calls a 'disciplinary matrix' [...] although elsewhere he often uses the term 'paradigm'.$^{50}$

Although originally developed in relation to natural science, and in particular to physics, this notion of paradigm has travelled far into the social sciences and, as in the case of Bourdieu's doxa, also into international law, where, for example, Mark Weston Janis has suggested using it as the 'meta-theory' of international law. ${ }^{5}$ David S. Koller has emphasized the role of paradigm specifically in relation to international criminal law..$^{2}$

In the context of the disappearing conditional ifs, it seems that our findings can actually provide (additional) empirical support for these claims about the

5o Alexander Bird, 'Thomas Kuhn' in Edward N. Zalta (ed), The Stanford Encyclopedia of Philosophy, Winter 2018 Edition, forthcoming) $<$ https://plato.stanford.edu/archives/win2or8/entries/thomas-kuhn/> accessed 6 November 20I8. Kuhn's paradigm theory was originally developed in his main work, The Structure of Scientific Revolutions (Chicago University Press 1996 [1962]).

${ }^{5}$ Mark Weston Janis, 'Sources in the Meta-History of International Law: A Little Meta-Theory-Paradigms, Article 38, and the Sources of International Law' in Samantha Besson and Jean D'Aspremont (eds), The Oxford Handbook of the Sources of International Law (Oxford University Press 20I8).

${ }^{52}$ David S. Koller, 'The Faith of the International Criminal Lawyer' (2008) $40 \mathrm{New}$ York University Journal of International Law and Politics IOI9, at IO32. Koller's use could be challenged in so far that Kuhn originally developed the notions of paradigm and normal science to explain scientific revolutions by which he understood transitions from pre-science to science or from one period of normal science to another (e.g. from Newtonian to Einsteinian physics). In the case of international criminal law, however, it seems that we are dealing with a paradigm and a normal science that came into being through specialization; a branching out from generic international law, or perhaps rather a merger between international humanitarian law (IHL), international human rights law (IHRL) as sub-disciplines of international law and criminal law as a sub-discipline in domestic law. However, it is commonly acknowledged that Kuhn's theory can also be used to understand specialization and in his later work, Kuhn himself focused increasingly on this phenomenon, cf. K. Brad Wray, Kubn's evolutionary social epistemology (Cambridge University Press 20II), notably Chapter 7: Scientific Specialization. 
existence of doxa and/or of a normal science paradigm in international criminal law. The steady decline in the use of ifs suggests the increasing confidence felt by the international criminal law actors in the beliefs constituting the conditions of meaningful discourse. Through the Bourdieusian prism, the first decades of the ad hoc tribunals' life witnessed the emergence of international criminal law as a new (sub)field, with the corresponding development and consolidation of doxa as the possibilitycondition of this field of opinion. Correspondingly, from a Kuhnean perspective, the decline of ifs corresponds to the transition of international criminal law as a discipline from pre-science to normal science and thus to the emergence and consolidation of an international criminal law paradigm.

\section{2. 'Law Was Once Introduced Without Reason, and Has Become Reasonable': The} Charge of Irrational Relativism

At the same time, the disappearance of ifs may also constitute an important challenge, or at least a corrective, to these sociological approaches, especially when it comes to an understanding of the epistemic micro-dynamics involved in the creation and consolidation of the paradigm/doxa of the emerging normal science/field. This point calls attention to some of the most contentious and debated exegetic issues in relation to the works of both Kuhn and Bourdieu. ${ }^{53}$ More specifically, both theorists have been accused of implying an irrational and ultimately untenable relativism. Before returning to our findings, this subsection explains this contention.

The discussion starts from the observation that both Kuhn and Bourdieu can at least be read as emphasizing a sharp dichotomy between what constitutes a discipline's condition of possibility (i.e. the paradigm or doxa respectively) and what takes place on the surface and immediately presents itself as the discipline. On this reading, the paradigm/doxa is not only silent in the sense emphasized by the generic philosophical view of legal knowledge, i.e. as a prologue that is no longer articulated but now merely tacitly presupposed in any given occasion. The paradigm/doxa itself is also unapproachable through rational analysis. This is precisely what makes the discipline autonomous and

${ }_{53}$ For some references, cf. notes 62 and 63 and below. 
what seals it off from other disciplines and makes it categorically inaccessible to outsiders.

In Kuhn's theory, this inaccessibility to outsiders is explained in relation to paradigm shifts in terms of the incommensurability of different paradigms:

$[T]$ he proponents of competing paradigms practice their trades in different worlds. [...] Just because it is a transition between incommensurables, the transition between competing paradigms cannot be made a step at a time, forced by logic and neutral experience. ${ }^{54}$

Koller emphasizes precisely this radical irrationality of the paradigm:

Kuhn illustrated the critical role played by faith in underpinning paradigms such as that of international criminal law. Faith-in the sense of belief in the absence of a sufficient rational basis-has a natural and essential role to play in all human endeavors where science and reason have been exhausted, or have not yet become available. The fields of law and criminology are no exceptions. 55

Again, we should observe that in international criminal law we are dealing with a new paradigm created through specialization; Kuhn's considerations about incommensurability explicitly relate to a shift between competing paradigms within the same science. However, as mentioned above (cf. note 52 ), it is common to extend Kuhn's considerations by analogy to the phenomenon of specialization, also in relation to incommensurability. ${ }^{56}$

Although admittedly a difficult interpretive issue, Bourdieu can at least be read in much the same vein, i.e. as highlighting the rational inaccessibility of doxa. In relation to doxa, Bourdieu thus emphasizes that 'what is essential goes without saying because it comes without saying: the tradition is silent, not least

${ }_{54}$ Kuhn (n 50) I50, emphasis added.

55 David S. Koller, 'The Faith of the International Criminal Lawyer' (2008) 40 New York University Journal of International Law and Politics IOI9, at I032.

${ }^{56} \mathrm{Cf}$. Wray (n 52) $\mathrm{I27}$. One might add that this follows by implication. If incommensurability is due to the fact that commitment to a given paradigm is irrational in the sense that it involves a leap of faith, then this paradigm remains rationally inaccessible to all outsiders of the normal science which it supports, regardless whether these outsiders are placed in a competing paradigm within the discipline, or whether they stand outside the discipline entirely. (We are grateful to one anonymous reviewer for pressing us on this point.) 
about itself as a tradition'. He continues to describe doxa as 'the aggregate of 'choices', whose subject is everyone and no one because the questions they answer cannot be explicitly asked', and as 'the sum total of the theses tacitly posited on the bither side of all inquiry'. ${ }^{77}$ Bourdieu's illustration of the relation between the fields of doxa and of opinion is shown in figure II.

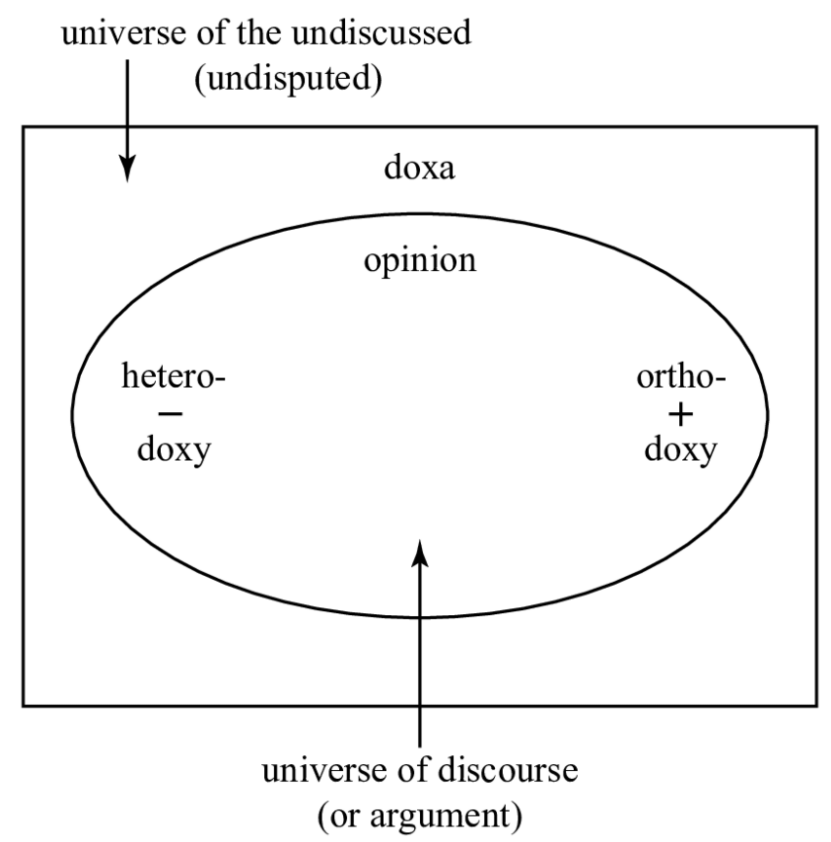

Figure II. Relation between the field of doxa and the field of opinion according to Bourdieu..$^{8}$

In his late work Pascalian Meditations (2000), Bourdieu developed these thoughts in relation to law, building in particular on the following statement by Pascal: '[The people] must not see the fact of usurpation; law was once introduced without reason, and has become reasonable. ${ }^{59}$ Bourdieu fully endorsed the anti-foundationalist, anti-Cartesian sentiments of these words:

Thus the only possible foundation of law is to be sought in history, which, precisely, abolishes any kind of foundation. At the origin of law, there is nothing other than arbitrariness (in both senses), 'the fact of usurpation', violence without justification. Genesis amnesia, which arises from exposure to custom, masks what is spelled out in the brutal tautology: 'law is law, and

57 Bourdieu (n 47, 1977) I67-I68, first emphasis in the original.

$5^{8}$ Bourdieu (n 47, i977) i68.

59 Pascal (from his Pensées), quoted in Bourdieu (n 47, 2000) 80. 
nothing more.' Anyone who wants to 'examine its motive', its raison d'être, and 'sound it even to its source', that is, ground it by going back to the first beginning, like philosophers, will never find anything other than this kind of principle of sufficient unreason. ${ }^{60}$

These passages from both Kuhn and Bourdieu invite a reading not only of the paradigm/doxa as impenetrable to rational argument but also of the explicit level, i.e. the day-to-day puzzle-solving of normal science/the ortho- and heterodoxy displayed in the field of opinion, as constituting the sole realm of reason or, in Bourdieu's words, the universe of discourse or of argument. The paradigm/doxa is that which renders rational discourse possible but which itself defies any rational contestation or reconstruction. Instead, the battle between competing paradigms/doxas is extra-rational, involving only pious faith and/or raw power.

\section{Empirical Support for Armchair Philosophers?}

Following this line of reasoning, one might naturally have expected the exact opposite development in the ICTY's and ICTR's language use from the one observed. Thus, going back to the beginning of the tribunals' existence, there was ex bypothesis no full-fledged paradigm/doxa of international criminal law. In their absence, one might have expected the early judgements to consist primarily of Bourdieu's 'brutal tautologies' - 'law is law, and nothing more' or of Kuhnean exclamations of faith. Conversely, at the time of the tribunals' closure, when ex bypothesis the paradigm/doxa was more firmly in place as the condition of possibility of rational discourse and contestation, one might have expected to find more closely argued texts.

As documented above, however, we have instead seen the opposite development. We have seen that the earliest texts in the corpus - where the fundamentals of international criminal law were not yet in place and where the paradigm/doxa was still being negotiated - were eminently rational, containing a large number of explicit conditionals and chains of arguments that could be reconstructed all the way down to the most fundamental level. And we have seen the opposite in the later development of the case law: a greater unwillingness to spell out all the premises of one's reasoning.

${ }^{60}$ Bourdieu (n 47, 2000) 80-8I. 
This observation challenges the strong relativism often associated with Kuhn and Bourdieu, not least by some of their proponents in international criminal law. It may be true that large parts of the discourse of the 'mature tribunals', i.e. the ICTY and the ICTR toward the end of their existence, are heavily 'truncated', in the sense that they do not make sense immediately as they stand but rather only against a backdrop (the paradigm or the doxa of international criminal law) which is unfamiliar to outsiders. However, according to our findings it simply seems empirically wrong to claim that this backdrop, understood as the most foundational beliefs of practitioners of international criminal law, should somehow reside in an extra-discursive universe and as such categorically escape rational reconstruction. On the contrary, and as exemplified most clearly in the Tadic decision on jurisdiction, which clearly states the foundational assumptions on which the field relies, ${ }^{6 r}$ it seems that the early case law is to a very high degree accessible to outsiders, precisely in virtue of the high frequency of conditionals.

It should be emphasized that this foundational reasoning of the court does not go all the way to the absolute axiomatic foundational level. We are not

${ }^{6 r}$ This is of course is not to say that these foundational assumptions are argued flawlessly, or that they are uncontroversial. The point is only that the line of reasoning in the early case law is more easily accessible to outsiders than the late case law.

This point is further corroborated by a close combined automated corpus linguistic and manual reading of the case law relating to one of the most controversial aspects of the ICTY jurisprudence, i.e. regarding the introduction of Joint Criminal Enterprise as a mode of responsibility. Thus, the ICTY discusses this doctrine in a number of judgements in response to challenges against this mode of criminal responsibility raised by defendants at different times throughout the ICTY's existence. The relevant case law falls in three periods: i) 1999; ii) 2003-2008; and iii) 20I4-20I7. Interestingly, the frequency of ifs used in these three period follows the general pattern closely although even more clearly with the following distribution per I00,000 words, i.e. 1999: 236 ifs; 2003-2008: 123 ifs; and 2014-2017: 54 ifs. Corresponding to this computer-based reading, however, the first judgements are immediately readable for outsiders openly embracing the controversial issue and arguing in general language the pros and cons of the doctrine drawing on a wide variety of different and non-specialized sources. This contrasts sharply with a reading of the case law constituting the final group which is far more impenetrable to lay readers with its widespread use of specialized legal language, references to the doctrine in abbreviated form ('JCE'), and prolonged discussions of technical matters of detail rather than the doctrine's fundamental raison d'être. 
claiming that the tribunal is searching, Cartesian style, for the Archimedean point of all knowledge. The tribunal only goes to the point where it can establish a solid connection between the controversial starting assumption inside the emerging field (jurisdiction over Tadić and other individuals) and the most closely related uncontroversial assumption in the world outside (pacta sunt servanda). This is sufficient to overcome the strong relativistic claim of incommensurability between paradigms.

In this sense, it seems, somewhat ironically, that the armchair philosophers referred to in the first sections of this paper do indeed seem to be closer than the sociologists to providing an empirically adequate understanding of the fundamental logic at play in the development of an epistemic community like the one constituted by international criminal lawyers. This by no means implies that it is not useful to invoke Kuhn's and Bourdieu's notions of paradigm or doxa to describe the autonomization and gradual emergence of a specialized field like international criminal law. However, in so doing, the temptation to infer strong relativism should be resisted.

As discussed above, the issue of strong relativism in Kuhn's and Bourdieu's respective theories remains contested and has inspired extensive commentary and critique. ${ }^{62}$ Furthermore, both Kuhn and Bourdieu seem to have struggled with the question themselves, especially in their later work, in which they both exhibit a certain uneasiness and impatience to reassure the reader against the most radical interpretations. ${ }^{63}$ Whether they have succeeded in doing so remains an open question. However, if our

${ }^{62}$ Especially Kuhn's notion of incommensurability has occasioned heated debate and raised deep exegetic discussions, cf. e.g. Léna Soler, H. Sankey, and Paul HoyningenHuene (eds), Rethinking Scientific Change and Theory Comparison (Springer 2008) and Ipek Demir, 'Incommensurabilities in the Work of Thomas Kuhn' (2008) 39(I) Studies in the History and Philosophy of Science I33. For a useful overview and discussion of Bourdieu's notion of doxa, cf. Deer (n 48 ).

${ }^{63}$ For Kuhn, see notably his 'Postscript - 1969' in Kuhn (n 50) and Thomas Kuhn with James Conant and John Haugeland (eds), The Road Since Structure (University of Chicago Press 200o). For Bourdieu, see e.g. Pierre Bourdieu and Loï J.D. Wacquant, An Invitation to Reflexive Sociology (Polity Press 1992) and especially Bourdieu (n 47, 2000), notably 9I-93, and Pierre Bourdieu, Science of Science and Reflexivity (University of Chicago Press 2004) which constitutes his final lecture course at Collège de France, and is devoted to the subject of science. 
interpretation of the results of the corpus linguistic study of conditional ifs is correct, they might seem to suggest a Solomonic way out of the cul-de-sac of strong relativism. Incommensurability and autonomy are real phenomena, but the sociology of knowledge and science is most fruitful when these are conceptualized in relative and not absolute terms. The crucial assumptions of the practitioners in the field may indeed be unconscious but they are still assumptions; the prologue may indeed be silent, but it is still a pro-logue.

\section{CONCLUSION}

The considerations presented in this paper were prompted by the findings in a computer-driven corpus linguistic study of all judgements from the ICTY and the ICTR from 1996 to 2017 . To our surprise, this study revealed that the frequency of the use of ifs in all judgements had exhibited a steady diachronic decline from 93 per I00,000 words on average in 1996 to 34 in 2017 . We submit that the combination of the philosophical and the sociological perspectives applied here has brought us closer to an explanation of this phenomenon. This explanation ties the waning use of ifs to the gradual emergence over the last couple of decades of international criminal law as a specialized kind of legal knowledge and expertise with its own distinct set of tacit philosophical premises constituting the field's 'substantial body of jurisprudence' and embedded in a distinct epistemic community as an empirical institutional fact. At the same time, the empirical findings also necessitate a reconsideration of our preexisting general theoretical understanding of the emergence of disciplinary knowledge and epistemic communities. In this way, the corpus linguistic study of the use of ifs has proven useful not only for a deeper understanding of the field of international criminal law.

On the assumption that international criminal law is not completely unique but is representative of any emerging field of specialized knowledge, it seems warranted further to assume that this study has the potential to contribute in interesting ways to the philosophy and sociology of knowledge and science. On these grounds, we further submit that corpus linguistic studies of the legal use of conditionals deserve greater attention in future research. With the added resources available in philosophy and sociology, we believe that the systematic study of frequency patterns across time in the use of conditional 
language in various epistemic fields constitutes a promising avenue of further study. In the first instance, we are thinking of (and have, in ongoing work, already partly begun) expanding the specific corpus linguistic approach applied here to other courts. Not only does it seem promising to look beyond judgements to decisions, as well as to other international criminal courts and tribunals, notably to the International Criminal Court. It would also seem obvious to look at the case law of other international and even national courts.

Furthermore, it could be interesting to expand the search for disappearing ifs to scholarly literature including textbooks. It is still an open question whether these different literary genres exhibit analogous behavior or whether they develop independently. Kuhn claimed that there was a significant difference between research literature and textbooks, and it could be interesting to see whether empirical findings support this claim. Regardless of the results, these findings would require further theorizing.

Finally, it could also be interesting to expand the approach to other scientific fields. For instance, it could be interesting to carry out corpus linguistic studies of $i f s$ in science journals during periods of generally agreed paradigm shifts (e.g. before and after Einstein). Natural science is a perhaps completely different ball game to international criminal law and law more generally. However, keeping in mind the ramifications of Kuhn's study, which originally dealt only with the history of physics, it could be interesting to see whether this corpus linguistic study of the role of conditional ifs in legal knowledge might have the potential conversely to enlighten our understanding also of other disciplines, including in the natural sciences. 